\title{
Supporting Adults with Intellectual Disabilities with Relationships and Sex: A Systematic Review and Thematic Synthesis of Qualitative Research with Staff
}

\author{
Maria Charitou $^{1} \cdot$ Ethel Quayle $^{1} \cdot$ Alan Sutherland $^{2}$
}

Published online: 16 July 2020

(c) The Author(s) 2020

\begin{abstract}
Staff working with individuals with Intellectual Disabilities (ID) play an important role in enabling them to fulfill their sexual and romantic needs. Given the lack of recent reviews providing a synthesis of qualitative research in this population, the present review explored how staff working with individuals with ID in a variety of capacities (e.g. support workers, service managers, nurses, educators, psychologists, social workers) perceived their role in relation to supporting sexuality and relationships. A systematic search of EMBASE, PsychINFO, MEDLINE, CINAHL, ASSIA and SCOPUS was carried out and identified articles were rated against inclusion and exclusion criteria, as well as quality criteria. Findings were analyzed using thematic synthesis. The application of criteria resulted in the inclusion of 15 articles. Four themes were identified: (a) "Attitudes towards sexuality and relationships: A right and a challenge", (b) "Responding to sexuality and relationships: A conflicted discourse", (c) "Uncertainty and lack of systemic support", and (d) "Influences on decision-making". Findings suggest that staff hold ambivalent attitudes and often respond inconsistently to issues relating to service users' sexuality. Role uncertainty, fear of accountability, lack of training and policy, as well as factors related to employing organizations and family caregivers were identified as barriers. The findings highlight the importance of providing training and supervision for staff in order to address ambivalent attitudes and anxieties, further developing national and local policy in relation to sexuality and relationships, and supporting family caregivers to meaningfully work alongside staff on issues relating to service users' sexuality.
\end{abstract}

Keywords Intellectual disabilities $\cdot$ Staff $\cdot$ Sexuality $\cdot$ Relationships $\cdot$ Synthesis $\cdot$ United Kingdom

Maria Charitou

s1373469@sms.ed.ac.uk

1 Clinical and Health Psychology, School of Health in Social Science, University of Edinburgh, Edinburgh, UK

2 NHS Lanarkshire Adult Learning Disability Service, Kirklands Hospital, Bothwell, UK 


\section{Introduction}

The previous decades have witnessed significant legislative and societal changes to the rights of individuals with Intellectual Disabilities (ID) including education, employment and social inclusion [1]. Although it is well established in the literature that individuals with ID have sexual needs and value relationships [2], the area of relationships and sexuality has not been at the forefront of the social inclusion agenda [3] and has only attracted attention in recent years. In the United Kingdom, policies such as "Valuing People" have emphasized the importance of relationships and sexual health for individuals with ID [4]. Research however, suggests that policy implementation is not always straightforward and as a result, the romantic and sexual lives of individuals with ID often remain unfulfilled and with fewer opportunities than their non-intellectually disabled counterparts [5].

In the United Kingdom, the implementation of de-institutionalization policies [6] has led to individuals with ID being supported by a wider range of community workers. This often includes direct support staff in supported accommodation and community services (e.g. advocacy organizations), as well as health and social care professionals. Individuals supporting people with ID in any professional capacity can influence their ability and opportunities to engage in romantic and sexual relationships. For example, individuals with ID tend to have limited social networks [7] and reportedly display poor knowledge on issues related to relationships, sexuality and sexual health [8]. As such, they often rely on support staff and professionals for emotional and practical support [7], as well as for guidance on issues relating to sexuality specifically $[9,10]$. Support staff can also directly influence service users' opportunities to pursue relationships, for example by determining the availability of private spaces in their environments or by imposing restrictions to social interactions $[2,11]$.

Attitudinal research in this area suggests that staff generally tend to hold moderately liberal attitudes towards the romantic relationships and sexuality of individuals with ID [12-15]. It should be noted, however, that such findings may be context-specific as there is some evidence to suggest that staff employed in inpatient settings demonstrate more conservative attitudes compared to those employed in community settings [16, 17]. Furthermore, findings of research in this area could be compromised by the use of self-report questionnaires, which can add a degree of self-report bias [18]. Some studies have found that staff of younger age tend to hold more liberal attitudes [10,12], however other studies have failed to identify age related differences [15]. More positive attitudes have also been linked to higher education level $[12,19]$ as well as to having received previous training in sexuality and having an understanding of relevant service policy [17, 20]. Limited evidence would also suggest that specific aspects of relationships and sexuality such as parenthood or same-sex relationships may attract more conservative attitudes [12, 17].

In recent years, a growing body of qualitative research has emerged in this field with the aim of exploring the experiences of staff in relation to supporting individuals with ID with relationships and sex. Although qualitative studies can complement existing quantitative research by exploring complex phenomena in more depth [21], a frequent concern is that such studies often become marginalized and are rarely used to influence practice and drive change [22]. In this context and to alleviate this concern, reviews and syntheses of qualitative research can be valuable in providing knowledge with depth, due to the use of qualitative designs, and breadth, by drawing together data from different studies and contexts [23]. Furthermore, the synthesis of qualitative research can draw attention to underlying 
processes not identified by individual studies, illuminate future research directions and facilitate the transfer of a volume of knowledge to inform practice [24].

Three reviews of qualitative research on staff experiences in relation to the romantic and sexual relationships of individuals with ID have been published to date $[11,25,26]$. In 2014, Rushbrooke and her colleagues [11] used meta-ethnography to review and synthesize the findings of 17 qualitative studies exploring the difficulties faced by paid (staff) and unpaid (family) caregivers in relation to the sexuality of individuals with ID. Chrastina and Večeřová [25] also conducted a brief review of both qualitative and qualitative studies exploring the issue of support for adults with ID in relation to sexuality from the perspective of individuals with ID themselves, close persons, carers, and staff. More recently, Brown and McCann [26] conducted a review and narrative synthesis of mixed literature, including seven qualitative studies, on the views and experiences of family caregivers and direct support staff (i.e. support workers) in relation to the sexuality of individuals with ID.

The findings of the aforementioned reviews suggested that paid caregivers held diverse views on the sexuality of individuals with ID [11, 25, 26] and their personal experiences and values impacted on their perceptions of sexuality [11]. Sexuality was generally described as a right, however it was often talked about as conditional upon certain factors [11] and as a source of risk due to the possibility of abuse and exploitation [11, 26]. All three studies also highlighted a conflict between paid caregivers' desire to support sexual expression for individuals with ID whilst protecting them from risk, which on some occasions arose from the use of the Internet and new technologies [26]. Two reviews highlighted that paid caregivers reported confusion regarding their role, lack of training and uncertainty surrounding service policy on ethically challenging topics such as that of sexuality $[11,26]$. This in some occasions led to high levels of anxiety for paid caregivers as well as to inconsistent responses to issues of sexuality based on 'unwritten' rules [11]. In this context, a need for development of policy and training opportunities for staff was emphasized in order for staff to be in a position to support service users with issues relating to sexuality $[11,25,26]$.

\section{Rationale for Current Review}

The findings of previous reviews in this area discussed above show the complexity of the role of staff in supporting the sexuality and relationships of individuals with ID and suggest that ethical dilemmas, conflicting attitudes and competing responsibilities are likely to impact on their practices. Such findings further highlight the need for an ongoing exploration of the role of staff as well as of underlying factors influencing decision-making, and this is what the present review aimed to achieve. In addition, the present review attempted to address certain limitations identified in existing published reviews. For example, as Chrastina and Večeřová [25], and Brown and McCann [26] did not carry out a qualitative synthesis of previous findings, the present review undertook a qualitative synthesis approach to allow for a more in depth reflection of staff experiences. Additionally, as all three previous reviews had a broad focus on both paid and unpaid (family) caregivers, this has perhaps not allowed for the unique barriers faced by each caregiver group to be illuminated separately and in sufficient depth. The current review therefore aimed to provide a more focused representation of available research on the experiences and views of staff by focusing on this group only. 
Furthermore, since the publication of all three reviews, a number of qualitative research studies concerned with staff experiences in relation to their role of supporting the sexuality of adults with ID have been published [27-32]. In their discussion regarding the necessity of updating qualitative systematic reviews, France and colleagues [33] concluded that the emergence of new research, potentially contributing novel concepts, warrants an update. As such, the present review aimed to provide an updated quality review and synthesis of existing qualitative research, including more recent literature.

\section{Methods}

\section{Inclusion and Exclusion Criteria}

Studies eligible for inclusion met the following criteria: (a) they were published primary research written in English and published up until October 2019, (b) employed a qualitative design or mixed methods design where the qualitative results were accessible and (c) focused on exploring how direct staff and professionals perceived the romantic and sexual needs of adults (over 18) with ID and supported them with romantic relationships and relational aspects of sexuality (intimacy, sexual knowledge, safety, contraception). Exclusion criteria included studies with a focus on: (a) medical aspects of sexual health (e.g. penile hygiene, HIV prevention), (b) risk reduction (e.g. sexually challenging/offending behavior, sexual abuse, sexuality in forensic settings) and (c) sexual education program evaluation. Due to the heterogeneity of the staff groups involved in existing research, in this review the term "staff" was used to describe a range of direct support staff and professionals (e.g. support workers, clinicians, nursing staff, educators, managers etc.). No staff groups were excluded on the basis of professional identity, as long as the focus of their interactions with individuals with ID was consistent with the inclusion and exclusion criteria. As the majority of studies did not specify the severity of the ID of the service users supported, the term "ID" was used to cover presentations ranging from mild to severe as per categorization using the ICD-10 [34] and DSM-V [35] systems.

\section{Search Strategy}

Search terms were developed through a review of the literature and discussion with an experienced librarian. These included the following search words using AND/OR techniques; learning OR intellectual AND disability OR disabilities OR disorder OR mental retardation $O R$ mentally retarded AND attitudes OR beliefs $O R$ experiences $O R$ understanding OR perceptions $O R$ views OR interviews OR knowledge OR opinion AND personnel OR staff OR clinician OR professional OR support worker AND romance OR romantic $O R$ relationship $O R$ sex $O R$ intimacy $O R$ love. Using the identified search terms, the main researcher conducted a systematic electronic search in October 2019. The following six electronic databases were searched; EMBASE, PsychINFO, MEDLINE, CINAHL, ASSIA and SCOPUS. It has been acknowledged that the successful identification of qualitative research through database searches depends on the quality and clarity of research titles and abstracts, as well as on the database indexing practices [36]. In order to reduce the risk of omitting studies relevant to the topic of review, the main researcher carried out a hand search by manually checking the reference lists of included papers and carefully searching for relevant articles across Google Scholar and key academic journals. 


\section{Data Extraction}

Descriptive information and summaries of main findings were extracted from each out of the 16 selected papers into a table by the main author. The following information was extracted: (a) the names of the main authors, (b) the focus of the study, (c) the country of origin, (d) the number and type of participants involved, (e) the method and type of analysis used, (f) a summary of qualitative findings and (g) a summary of identified themes and subthemes.

\section{Quality Appraisal}

The growing recognition of qualitative research as having the potential to valuably contribute to evidence-based practice has led to the development of methods aimed at critically appraising its quality [37]. This is particularly relevant when conducting systematic reviews, as their overall quality partly depends on the quality of included studies [38]. In the present review, the quality of all included studies was assessed using the Critical Appraisal Skills Programme (CASP) qualitative tool [39]. The CASP provides a ten-question checklist-based framework for assessing the quality and rigor of selected studies and is widely used for the purposes of the quality appraisal of qualitative research [40]. In order to enhance rigor and minimize the potential for error, a second researcher independently reviewed a randomly selected number of papers using the same quality criteria. As CASP does not provide a system according to which ratings can be categorized, for the purposes of the present study the numerical scoring system and global quality ratings introduced by Butler, Hall and Copnell [41] were utilized in order to facilitate the comparison of ratings between the two raters. Based on their performance against the CASP criteria, articles were assigned ratings of "low", "moderate" and "high".

\section{Synthesis of Findings}

In a recent publication of the Cochrane Qualitative and Implementation Methods Guidance, Noyes and colleagues [40] reviewed thematic synthesis [42], framework synthesis [43] and meta-ethnography [44] as the most commonly used approaches for qualitative evidence synthesis. They concluded that thematic synthesis was the most accessible and clear method of analysis, followed by framework synthesis, whereas meta-ethnography required more caution in its use due to its complex methodology and unsatisfactory current reporting guidelines. Accordingly, thematic synthesis was selected as the preferred method of data synthesis. The process of thematic synthesis involved the three steps proposed by Thomas and Harden [42]; free line-by-line coding of text to produce free codes and identify key concepts, organization of free codes into descriptive themes and development of broader analytical themes. In line with the recommendation of Thomas and Harden [42], the coding process included data labeled as "results" or "findings" and referred to both verbatim quotes and themes identified by authors. The process of coding for each paper led to the production of a bank of codes. On the basis of their similarities and differences, as well as identified relationships between codes, these were arranged into descriptive themes through a process of assimilation and creation of new themes when necessary. The 
final step involved the development of higher-order analytical themes, which sufficiently reflected and explained the subthemes as a whole.

\section{Researcher Reflexivity}

The value of remaining mindful of potential prior beliefs or prejudices that could impact on data interpretation when reviewing research has been highlighted in the literature [40]. Although such influences cannot and should not be entirely eliminated, a commitment to reflexivity ensures that they are being accounted for [45]. As the main author has worked with individuals with ID in a clinical capacity, it is possible that these experiences may have impacted on the present synthesis in terms of what areas were focused on or perceived as important. To mitigate this risk, the main author remained mindful of this potential influence by continually checking themes produced by the analysis against the original papers in order to ensure they remained reflective of the dataset.

\section{Results}

\section{Screening Process}

The screening process involved the stages recommended by the Preferred Reporting Items for Systematic Reviews (PRISMA) protocol [46]. These are diagrammatically displayed in Fig. 1. An initial search across all databases yielded 8117 records. After removing duplicates, a total of 4732 records were screened for relevance and out of these, 4651 records were excluded on the basis of their titles and/or abstracts. When an abstract was not descriptive enough, the full text was screened. A remaining 81 records were reviewed in full text to determine their eligibility. During this process the main researcher contacted a number of authors to establish the publication status of identified papers (e.g. abstracts published in conference proceedings) and these were retrieved in full-text where possible. Following full text review, 13 records were deemed eligible and 68 records were excluded on the grounds of exclusion criteria. Four further records were identified through the main author's manual search of key journals and Google Scholar, leading to a total of 17 articles. Further review of the 17 articles identified revealed that two of the selected papers [27, 28], were separate publications originating from the same primary research. Although these had a somewhat different focus, a review of their content indicated that there was a significant degree of overlap. As one of these two articles [27] provided a richer description of concepts represented in both studies, a decision was made to retain only that article.

\section{Quality Assessment}

For the purposes of quality assessment, the main author carried out quality ratings and a second reviewer independently completed ratings for a random sample of 50\% of included papers to verify inter-rater reliability. This process indicated $86 \%$ interreviewer agreement. The kappa coefficient was calculated to account for the probability of agreement occurring on chance alone and the calculated value $(\mathrm{K}=.67,95 \% \mathrm{CI}$ [0.36-0.99]) suggested an adequate level of agreement [47]. In instances where there were disagreements in ratings, these were resolved through discussion. Assigned scores 


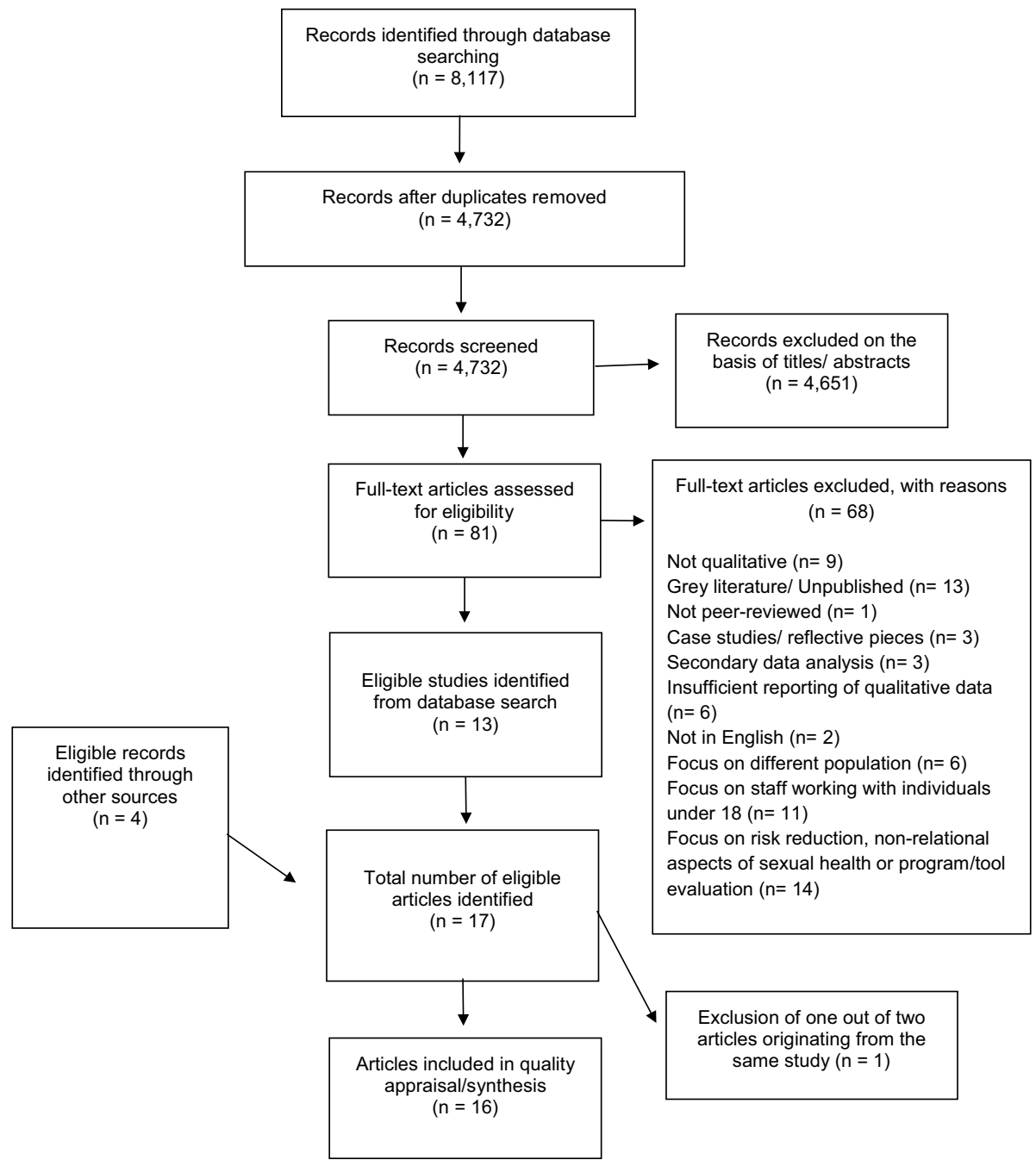

Fig. 1 Search process flowchart based on the PRISMA Group [46]

and global ratings are illustrated in Table 1. Five studies received "high" global quality ratings [27, 31, 32, 48, 49], nine received "moderate" global quality ratings [29, 50-57] and two received "low" global quality ratings $[30,58]$. Butler and colleagues [41] recommend that studies scoring less than six be excluded from reviews. In this review, one study [58] achieved a score of five. There is much debate in relation to whether quality appraisal should determine inclusion or exclusion of articles [59-61]. Although it is acknowledged that the use of a numerical threshold as a cut-off criterion has its limitations [59] and that low scores can be reflective of poorly reported as opposed to poorly conducted research [62], in the present review quality ratings determined inclusion and exclusion, and the article by Hamilton [58] was excluded. 


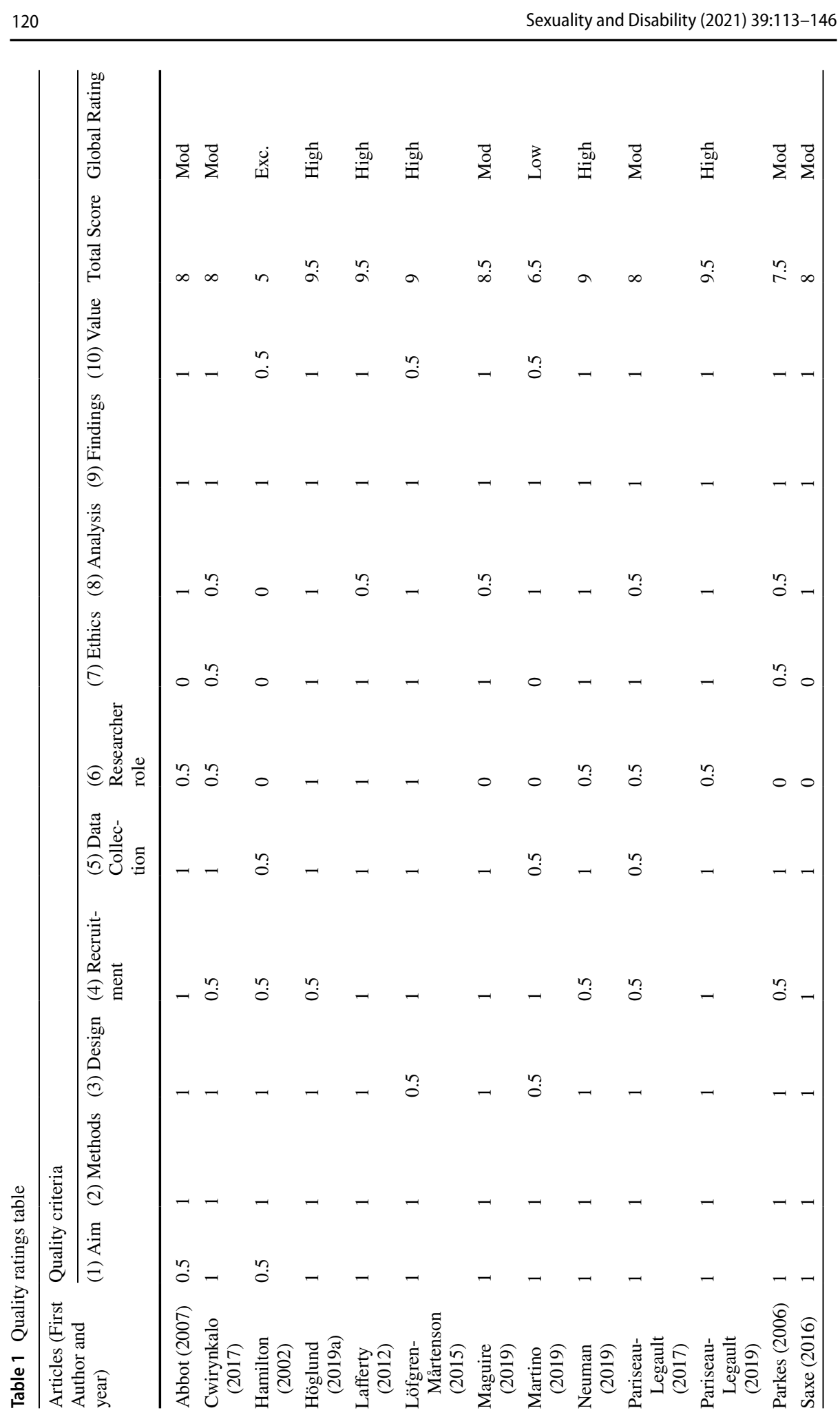

型 Springer 


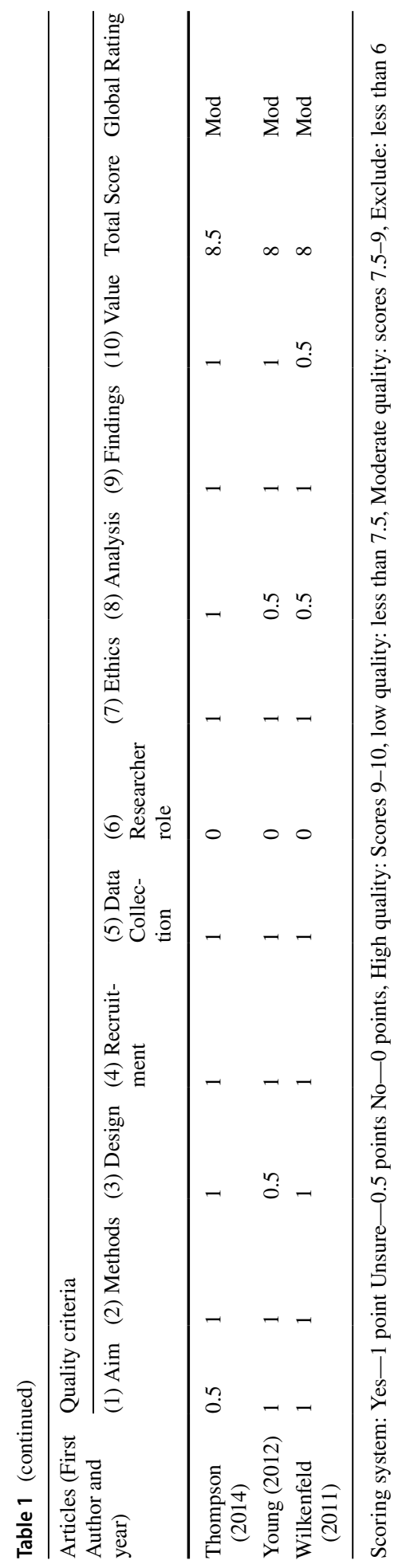




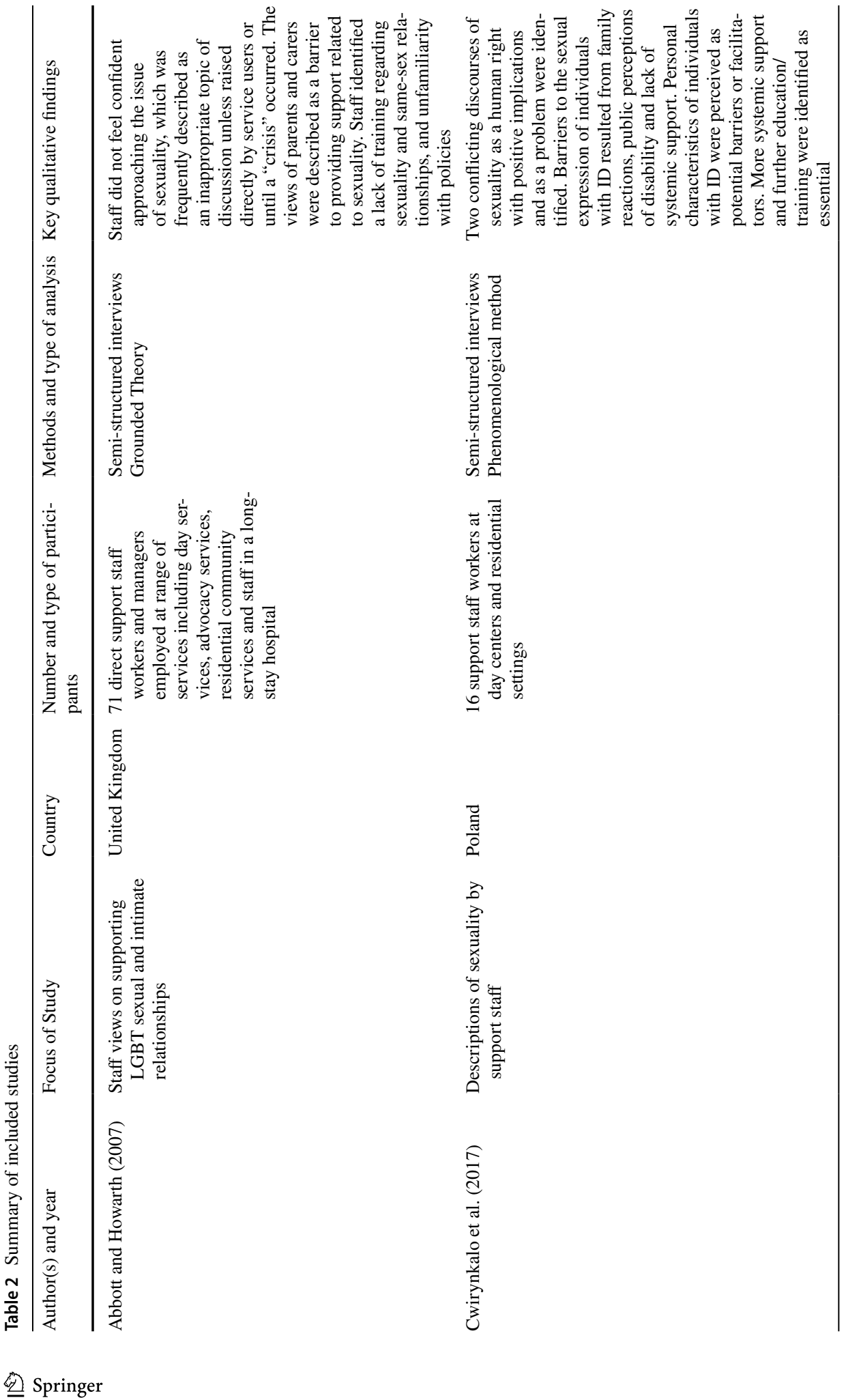




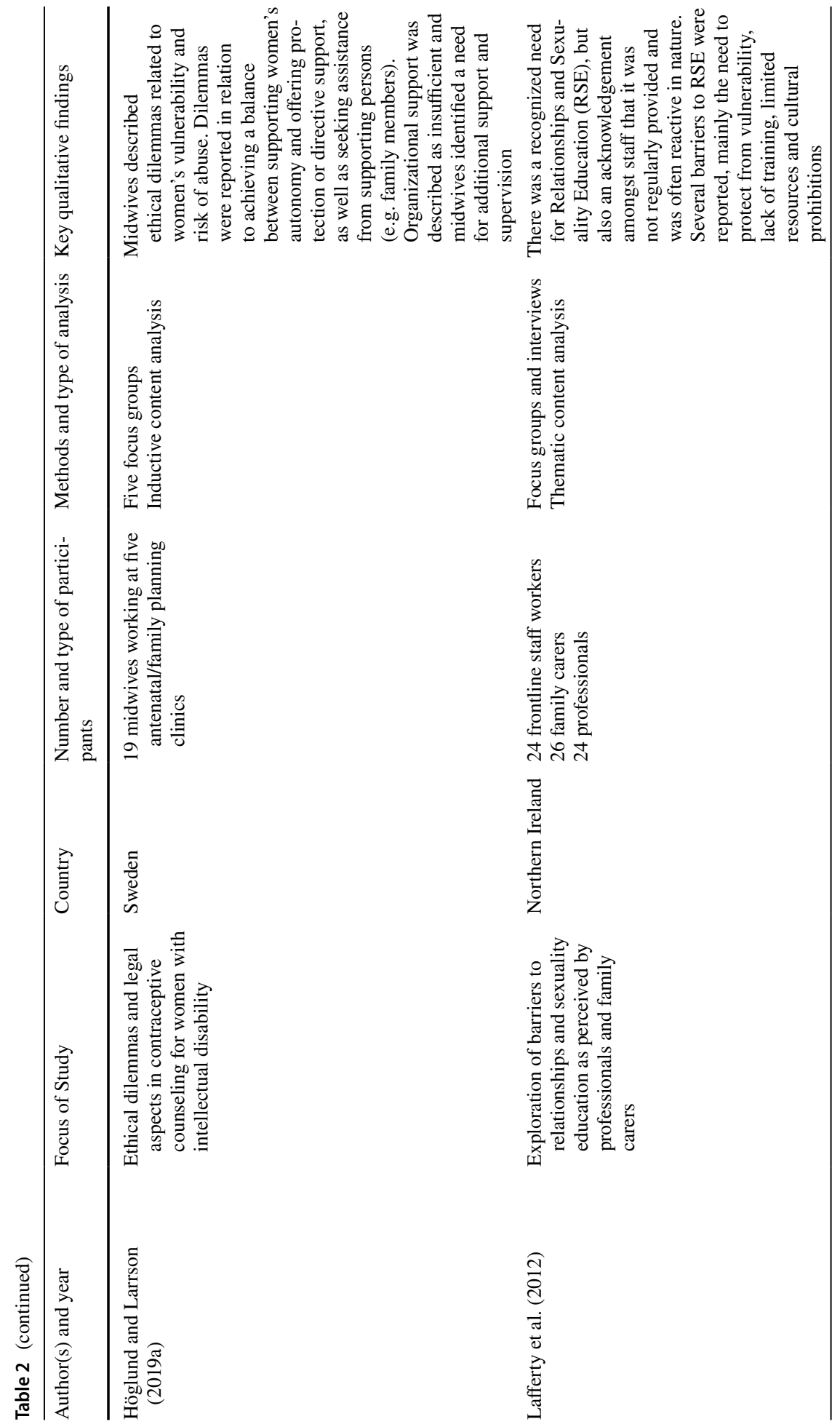




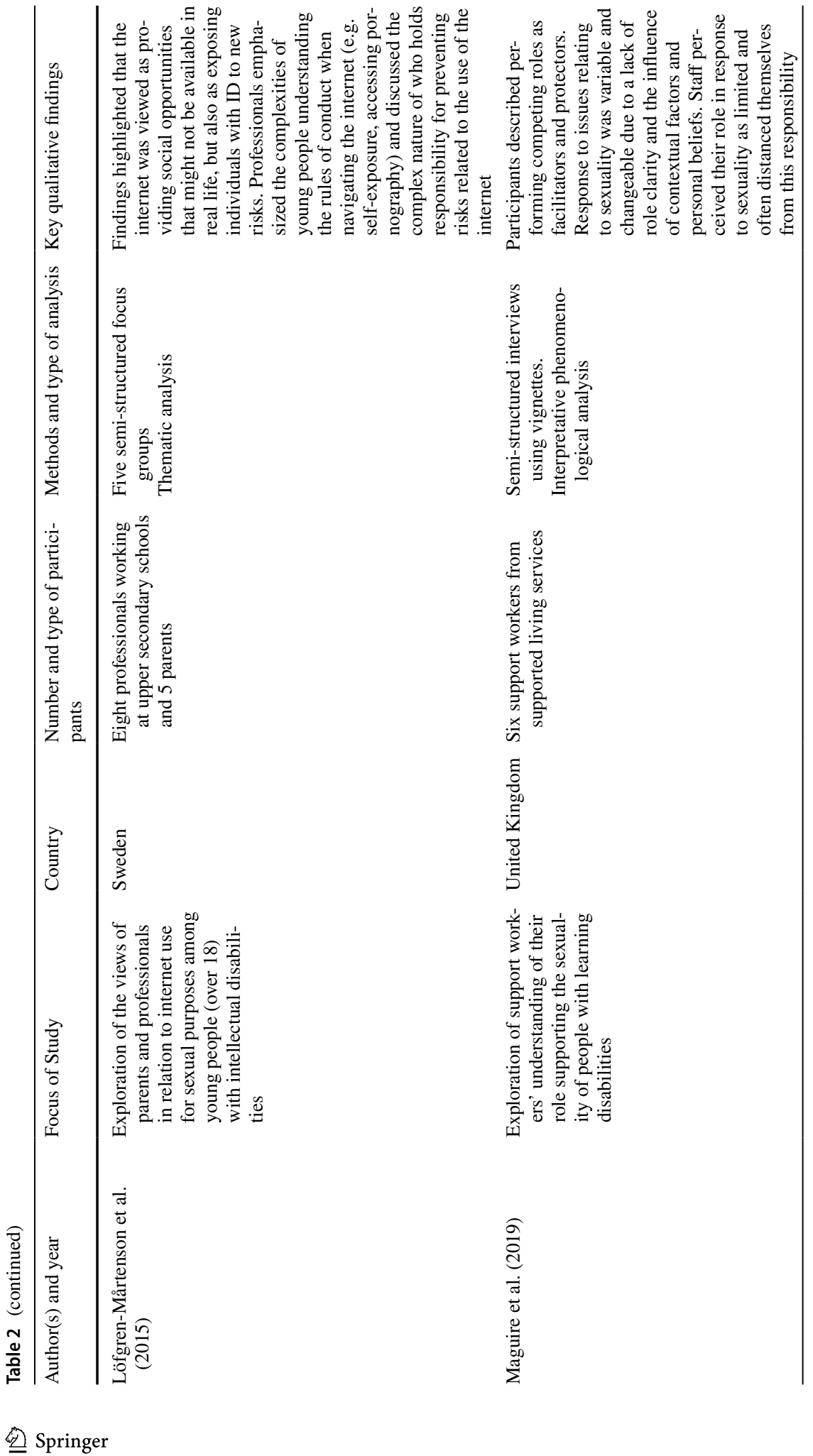




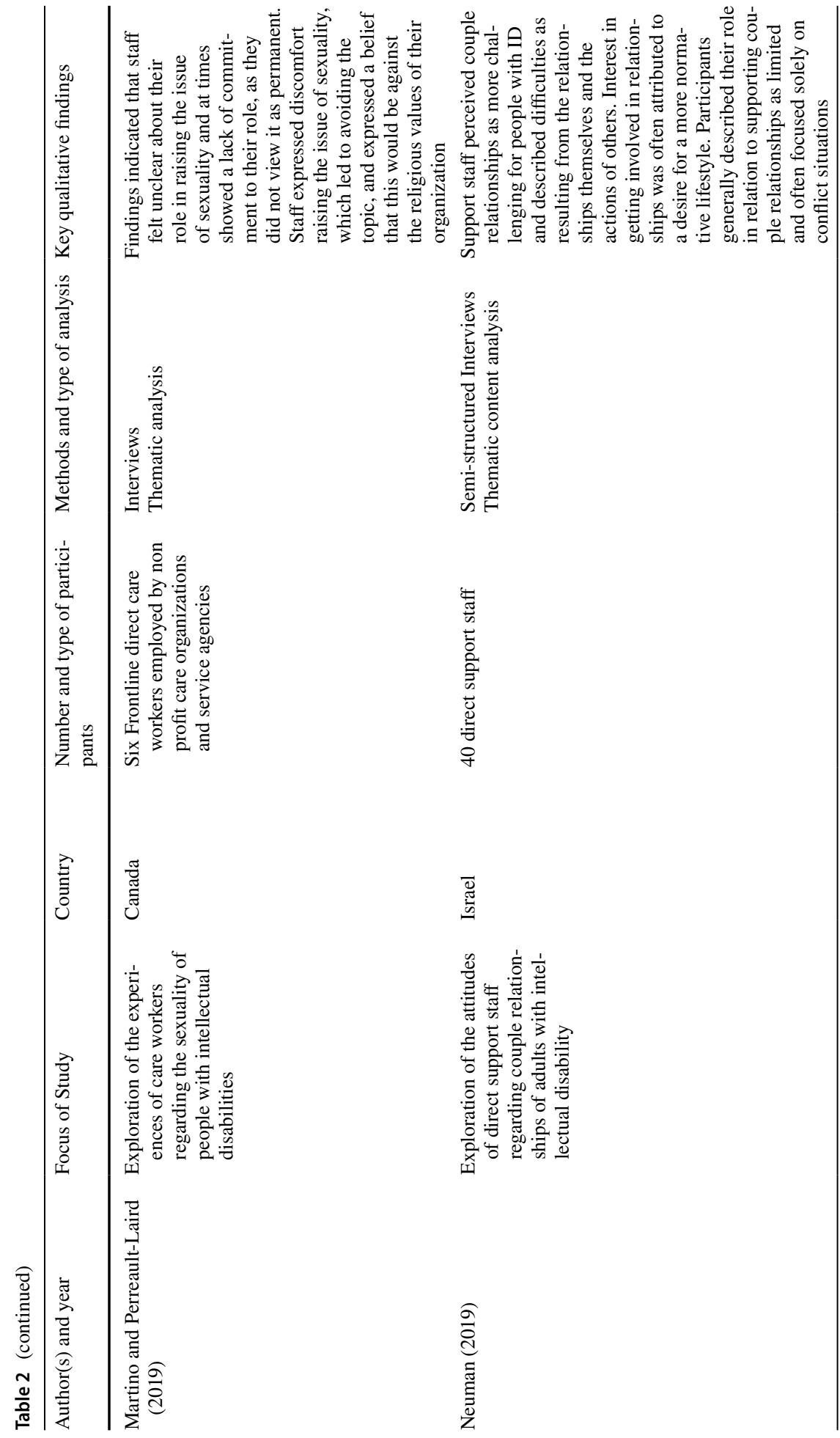




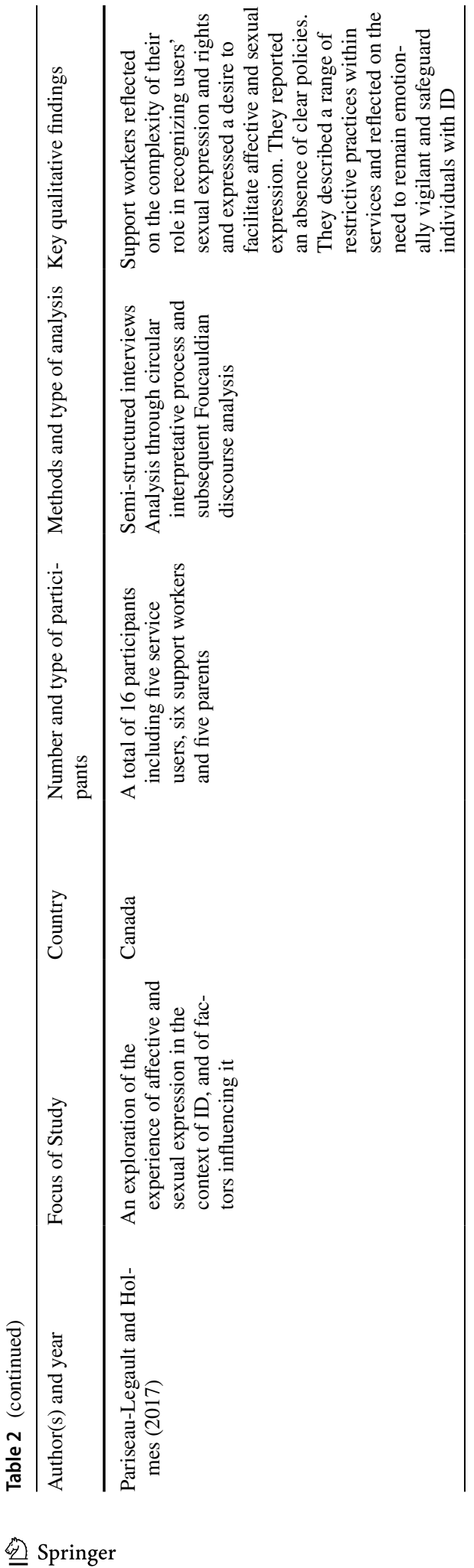




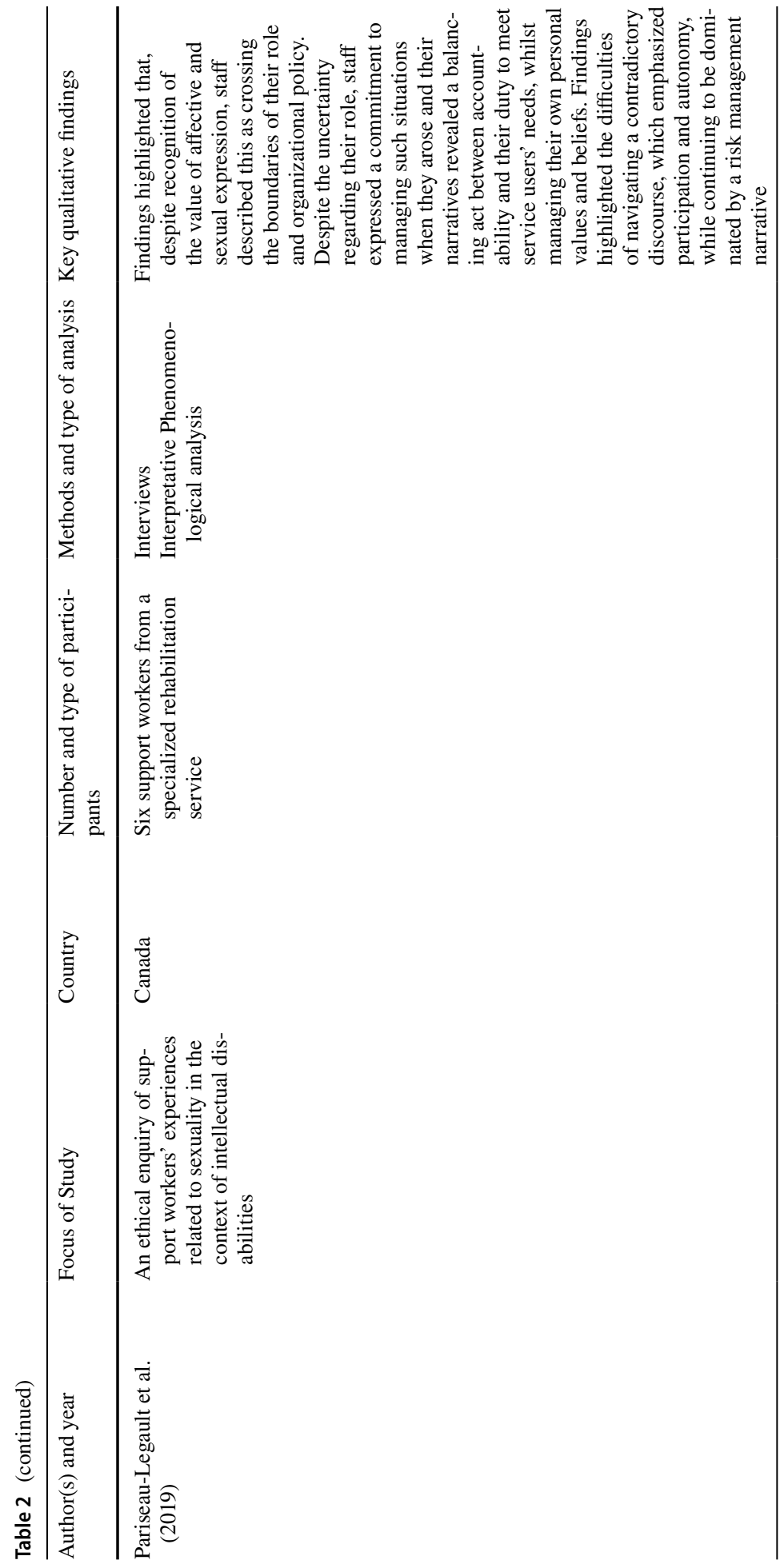




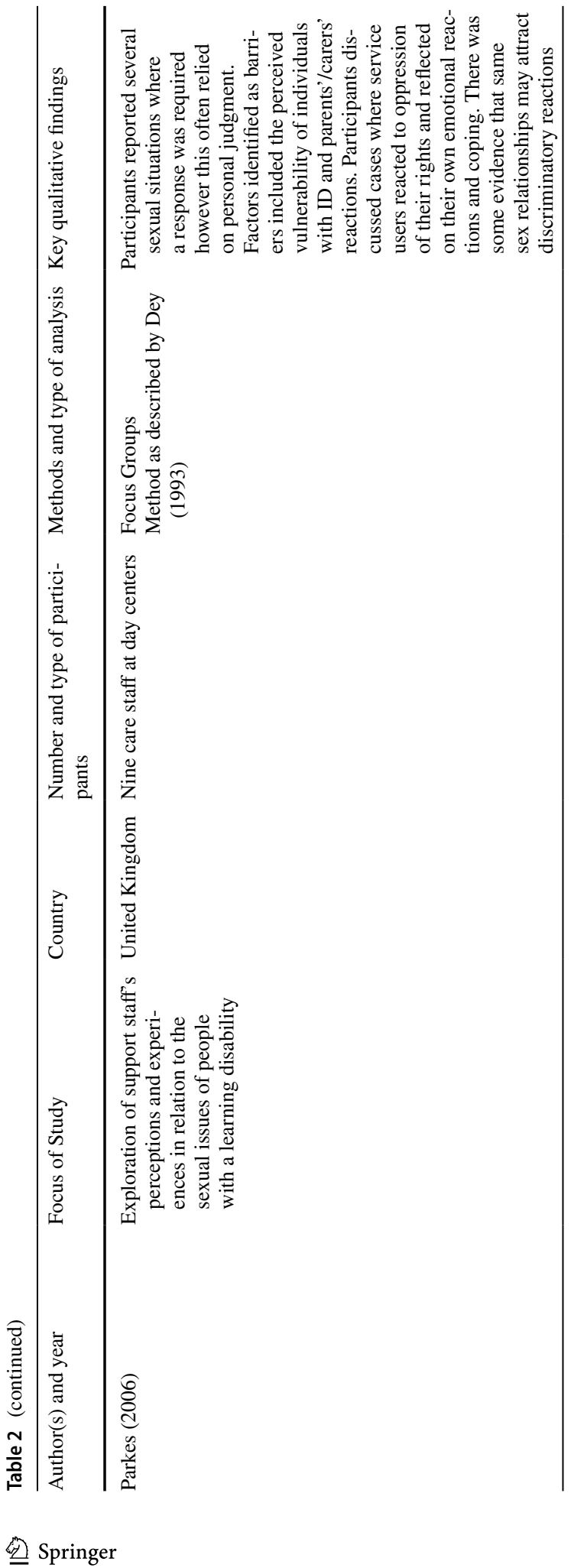




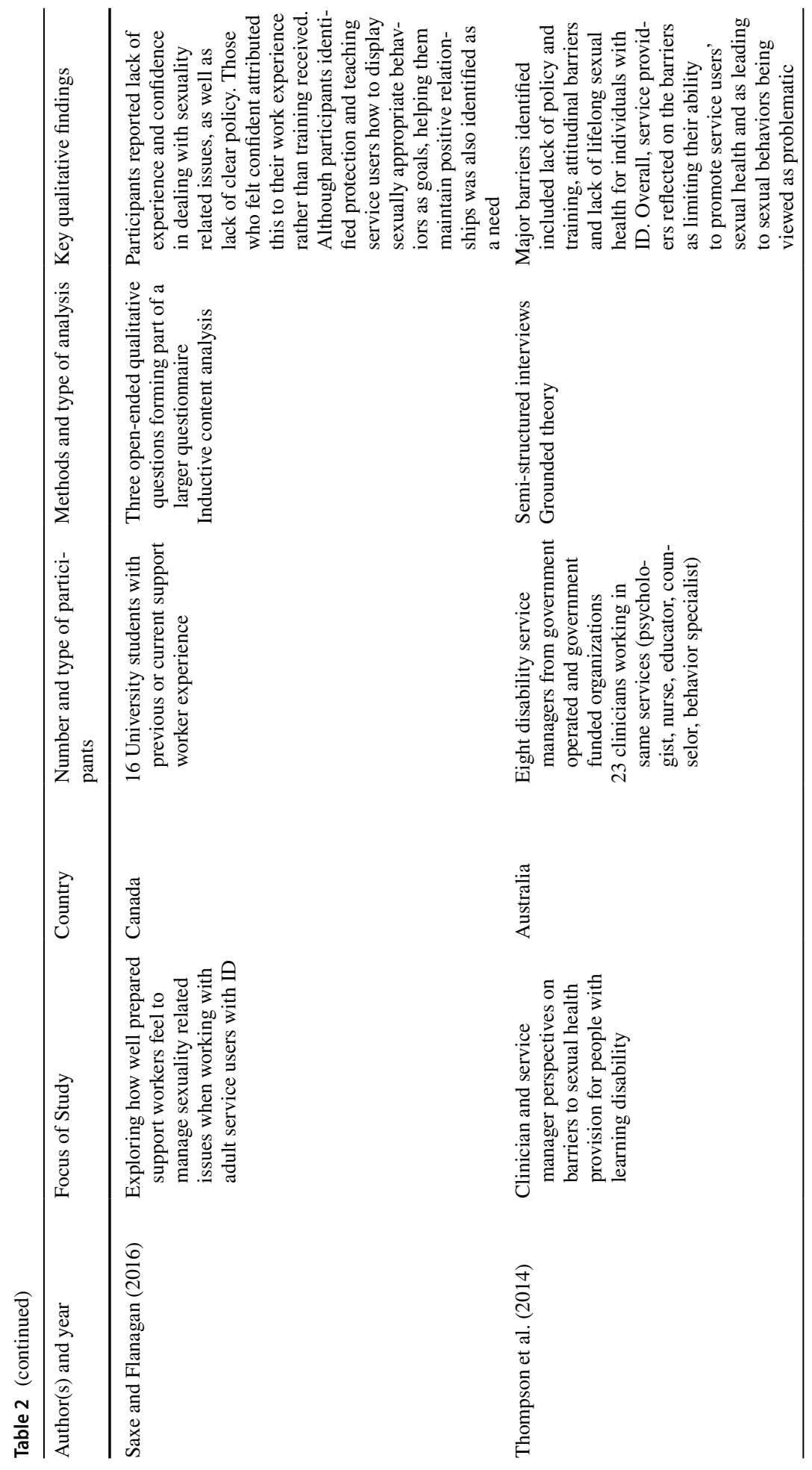




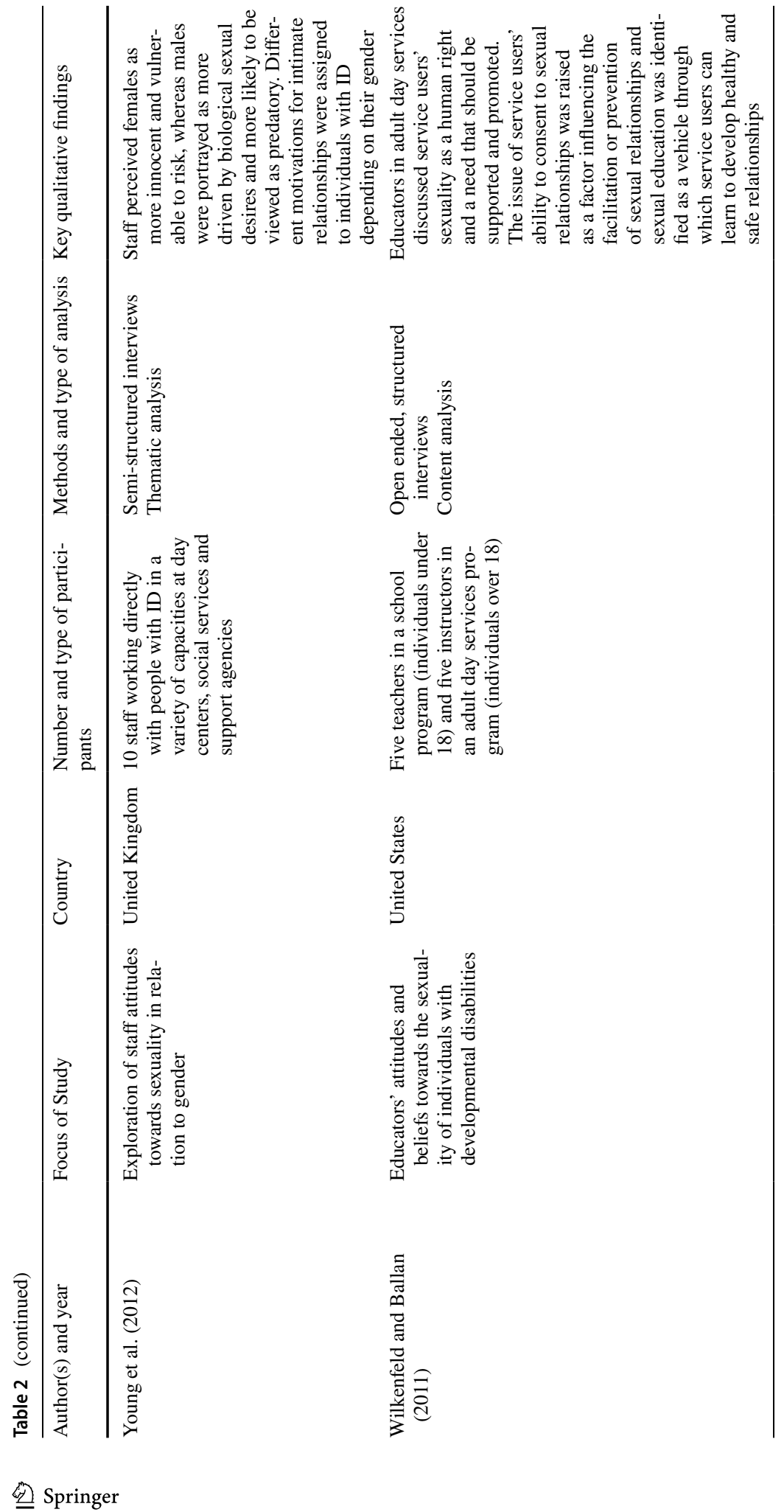




\section{Characteristics of Included Studies}

Extracted information regarding papers included in the review can be found in Table 2 . All 15 studies used qualitative methodology; ten used interviews for data collection, three used focus groups, one combined interviews and focus groups and one used a qualitative questionnaire. A variety of methods were used for data analysis, including thematic analysis, grounded theory, content analysis, interpretative phenomenological analysis, discourse analysis and methods of analysis drawing from phenomenology. A total number of 297 staff participated across studies. This included 129 support workers, 13 educators, 19 midwives, eight ID nurses, five social workers, eight ID service managers and 115 professionals of unspecified mixed backgrounds, such as nurses, support workers, educators, psychologists and clinicians. Some studies collected data from staff and other populations, such as family carers or service users [48, 49, 55]. For the purposes of this review, only data collected from staff was included in the analysis.

\section{Thematic Synthesis}

The process of coding produced a total of 49 codes. In order to group codes into descriptive themes, similarities and differences were considered and this process yielded a total of eight subordinate descriptive themes. While other methodological approaches that examine the recurrence of themes give clear guidelines regarding the frequency with which themes need to appear across the dataset in order to be considered representative [63], no such guidelines have been explicitly stated for thematic synthesis. As articles included in this review reported relatively consistent findings, all descriptive themes were represented in at least half of the included articles and are therefore likely to be reflective of the dataset as a whole. Thomas and Harden [42] acknowledge that, although descriptive themes produced from the analysis can be similar to the themes of the original studies, thematic synthesis aims to "go beyond" the content of original studies. This was achieved by using the descriptive themes to address the research questions under review, with an understanding that the creation of more abstract themes would depend on the researcher's insight and judgment [42]. This process led to the creation of four abstract and analytical themes, which were refined until they reflected the eleven produced subthemes sufficiently. The final superordinate and subordinate themes are shown in Table 3, alongside contributions from each included article.

\section{Attitudes Towards Sexuality and Relationships: A Right and a Challenge}

The majority of included studies found that staff provided a conflicted discourse when reflecting on their attitudes towards the sexuality and relationships of individuals with ID, with their narratives generally portraying romantic and sexual expression as a human right as well as a challenge and a source of risk.

\section{Subtheme 1: A Right and a Universal Need}

Staff in nine studies described the sexuality and relationships of individuals with ID as a human right that should be respected and promoted within services and organizations [27, 29-32, 48-51, 54, 57]. In some cases, there was an acknowledgement that these rights 
were violated or disrespected, and often this triggered feelings of frustration and anger for staff [49, 51, 54, 57]: "You know what I mean, I'd hate for anybody to miss out because I think it's such a wonderful thing. I just feel so frustrated sometimes when I think this is what they want and people are stopping them" [51, p. 35].

Fewer studies focused on the emotional or social value of relationships in the lives of individuals with ID. Those who did, described involvement in sexual and romantic relationships as not only meeting physical needs, but also as having the potential to meet a range of emotional and social needs for individuals with ID [27, 31, 49, 54, 57]. For example, involvement in relationships was in some cases described as reducing loneliness and giving the individual a sense of shared purpose: "I'm really in favour of their relationships. They really function better when they are in a relationship. They've got someone to live for." [54, p. 80]. Additionally, involvement in couple relationships was described as a status symbol and expression of normality [31,48]: "It seems to be a way of feeling recognition somehow... to show who you are and... how many girls and boys you have met... how much sex you have. Again, it's this thing about being "normal"” [48, p. 537], as well an opportunity for individuals to develop and learn from others: "Couple relationships is an opportunity for personal, social, and communication development” [31, p. 6].

\section{Subtheme 2: A Problem and a Source of Risk}

All studies reported that the sexual needs of individuals with ID were often also viewed as a source of risk [27, 29, 31, 32, 48-50, 52-57], mostly due to service users' vulnerability and the possibility of abuse and exploitation within their relationships. As the following extract suggests, staff attitudes were generally largely conflicted and echoed a commonly reported ethical dilemma between protection and sexual autonomy, and the implications this could have for the potential violation of service users' rights: "He has the right to a sexual life (...) Why not? But at the same time, there's this whole aspect of making sure that no one is at risk. Yes, he has sexual needs, so of course I'm concerned about it. But how far does it go? What rights do we have to stop this service user from experiencing sexuality?" [32, p. 122].

Sexual behavior was also often described as inappropriate and problematic $[32,50,52$, 54, 57] or 'childlike' [29]. In some studies, staff expressed ambivalent or negative views towards the issue of parenthood for individuals with ID [32, 54, 57]: “I don't think it's fair to have somebody who is disabled themselves and can't take care of themselves... I don't mind sex but the pregnancy is not fair to the child...' [57, p. 357]. Similarly, other studies suggested that involvement in same-sex relationships was not viewed as a conscious choice made by in individuals with ID or a legitimate expression of sexuality [51,52] and was met with higher levels of anxiety compared to opposite-sex relationships [56]. Notably, some studies highlighted that, although their participants had generally expressed supportive views about the sexuality and relationships of individuals with ID, these were not necessarily representative of staff attitudes in their organizations overall [51-54]: "Well, a lot of the group homes there's no real barriers there except for staff attitudes, but they're more of an attitudinal barrier that they actually stop the training from happening" [53, p. 143].

\section{Responding to Sexuality and Relationships: A Conflicted Discourse}

When reflecting on their own role in supporting the sexual and romantic lives of the individuals with ID they worked with, staff narratives often echoed an ambivalent stance. This 


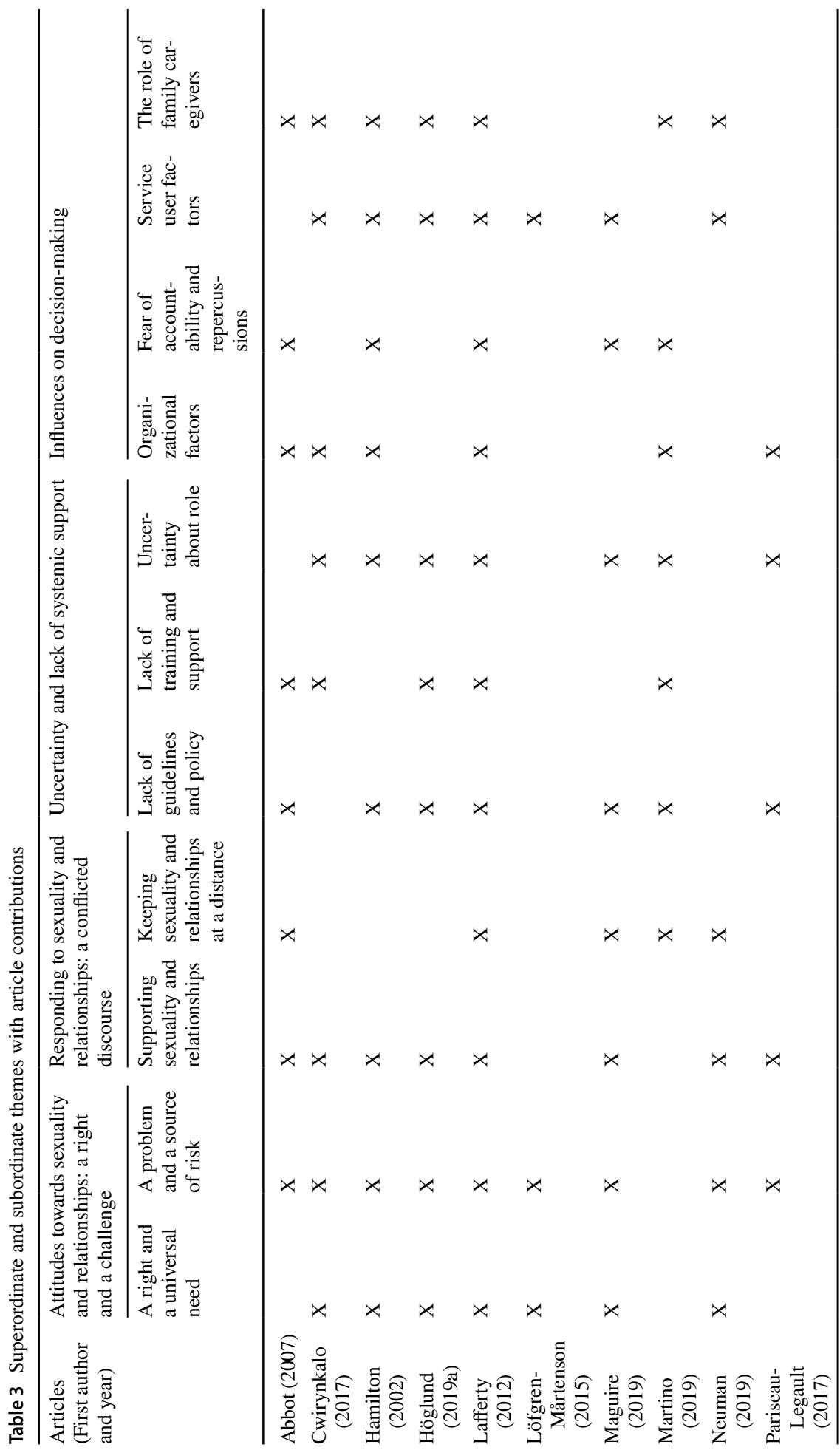




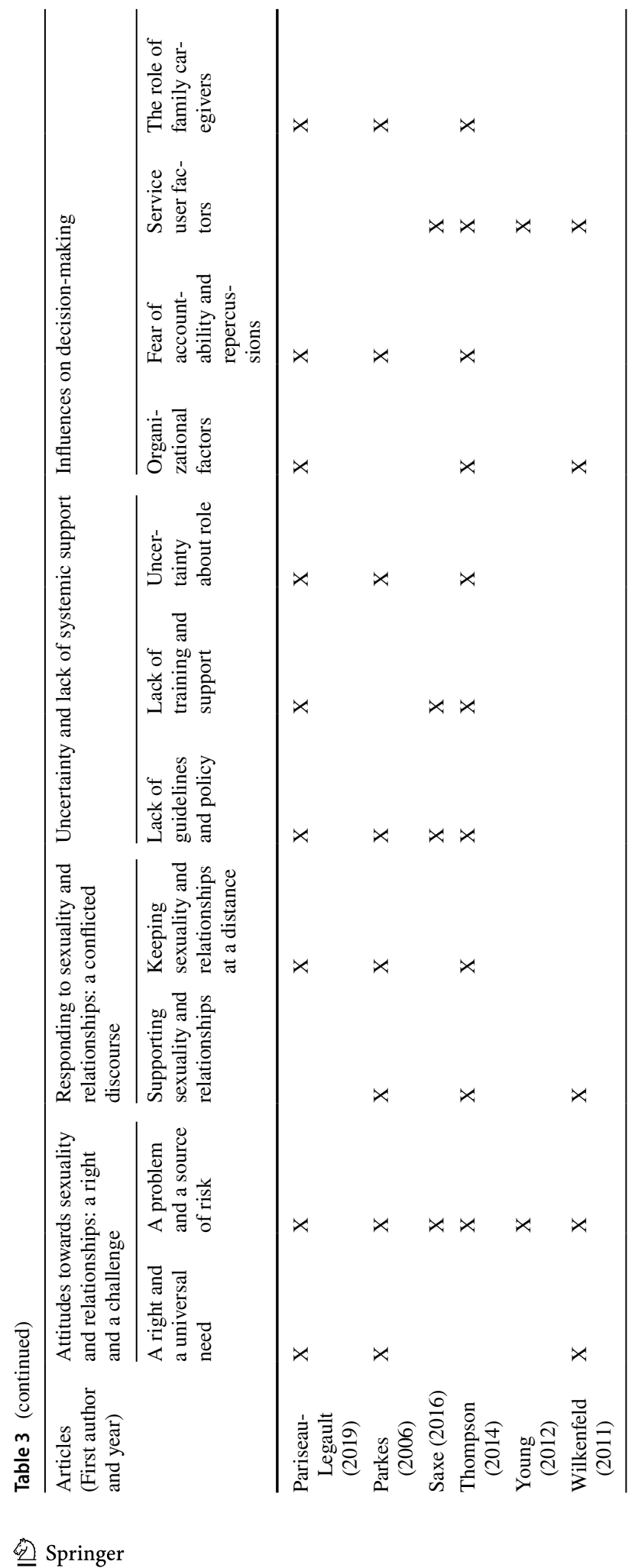


fluctuated between the recognition of their ongoing role in supporting service users with such matters as well as a tendency to avoid dealing with sexuality directly or only deal with issues surrounding sexuality and relationships in a reactive as opposed to a proactive manner.

\section{Subtheme 1: Supporting Sexuality and Relationships}

Staff in ten studies expressed a desire to support individuals with ID with issues related to sexuality and relationships [27, 29, 31, 49, 51-55, 57]. For example, they commonly described that individuals with ID held poor sexual socio-sexual knowledge and recognized their potential role in helping them develop such knowledge and skills through sexual education [31, 49, 52, 54, 57]. The following extract suggests that in some cases staff felt a sense of responsibility to approach the topic of sexuality and relationships even if they were not necessarily expected to: "But I feel obliged to widen it [the curriculum]. I don't feel I could teach fairly to students for a year and not bring in themes like sexuality. You know you spend hours talking about the rights to money and the rights to Giro (i.e. bank credit or checks), the rights to a safe working environment, when actually very few of our students really have an awareness of their money, or are going to go into paid work. But $90 \%$ of my students will at some point have a relationship" [52, p. 120].

Staff across seven studies shared experiences of supporting service users with matters relating to sexuality and relationships in several informal ways in their day-to day interactions with them. This most often involved helping them build socio-sexual knowledge and skills [27, 31, 49, 52, 55, 57], providing direct advice regarding relationships and sexual expression [29, 31, 52, 55, 57], supporting them with sexual health and reproduction [27] and enabling them to widen their social circle and meet potential partners [52]. Unsurprisingly, in the majority of studies staff described their role as aiming both at promoting sexuality and protecting individuals with ID in order to make sure they expressed their sexual and romantic needs safely [27, 29, 31, 32, 49, 51, 53, 54, 57]: "I would...say you know 'it sounds like this is something you're interested in (watching pornography), it's something you'd like to be doing. It is an adult thing to be doing and looking at and you are an adult now. It's about exploring how to do that in a safe and protected way" [29, p. 61].

\section{Subtheme 2: Keeping Sexuality and Relationships at a Distance}

While most studies highlighted that staff did get involved in supporting the sexuality and relationships of service users, in eight studies staff reported that in their services there was also a tendency to avoid dealing with sexuality directly [29-32, 49, 51-53]. For example, in some cases staff reportedly redirected such conversations or avoided proactively engaging with sexuality unless service users initiated it [29, 52, 53], suggesting that otherwise these needs remained overlooked: “They've actually got to instigate it. It's not something we offer as a suggestion. It's not something we tend to discuss very much with the clients at all [53, p. 143]".

Similarly, other studies reported that sexuality tended to be overlooked unless a response was necessary due to a problematic situation or an overt issue that could no longer be ignored [31, 32, 49, 52, 53]: "The only times we talk about it are when it's problematic (...) If there's a problem related to sexuality, it will be addressed. If there is no problem, it will not be discussed and we will work on something else instead" [32, p. 120]. Such findings suggest that there is likely a high degree of ambivalence in relation to the way staff respond to such needs. 


\section{Uncertainty and Lack of Systemic Support}

A consistent finding across the majority of included studies was the lack of clear guidelines regarding staff roles and responsibilities in relation to supporting sexuality and relationships in particular, as well as a lack of training opportunities and access to information and support. The lack of guidelines and training often created a great deal of uncertainty amongst staff regarding their role in supporting sexuality and relationships.

\section{Subtheme 1: Lack of Guidelines and Policy}

Ten out of fifteen studies reported that the services and organizations where participants worked lacked clear policy guidelines specifically in relation to managing the romantic and sexual needs of the individuals they supported [27, 29, 30, 32, 49, 51-53, 55]: "(Sexuality) is not really defined. (...) This is really my personal opinion, because it's not even in our job description. There are a lot of gray areas, other things that we do that aren't there. Maybe someday it will be included. (...) We might have to think about it as part of our basic needs" [32, p. 120]. In some cases, where staff believed that policies might have been available, they remained unfamiliar with these $[30,50,52]$ or did not mention them as overly relevant to their everyday practice [51].

In some cases, staff were only familiar with content relevant to what they should avoid doing when dealing with sexuality or with content focused on protecting individuals from potentially abusive situations [53]: “Ah, we don't really have any (policies) that I'm aware of, other than the client/staff policy about we're not allowed to have a sexual relationship with the clients" [53, p. 141]. Staff in three studies reflected on the value of policies within services and organizations and stated that further policy development was necessary in order for them to have a clear understanding of how to fulfill their roles [27, 49, 52].

\section{Subtheme 2: Lack of Training and Support}

In eight studies, staff described the training they had received on issues surrounding the sexual and romantic expression of the individuals they supported as extremely limited or absent [27, 30, 49, 50, 52, 54]: "Since I started working with disability in 2008, I've received no sexual health training and I'm now the supervisor." [53, p. 142]. This, in turn, limited their confidence in their ability to respond to such needs appropriately [27, 49, 50, 52, 53]. Two studies also highlighted that the limited training opportunities available had focused exclusively on the prevention of abuse [30, 49], as opposed to promoting positive socio-sexual skills: "We participate in watching a video which is-needs to be changesabout abuse and prevention of sexual abuse. But in terms of their rights to be sexually active, we really don't have a lot of about that, they (the agency) kind of stay away from that subject" [30, p. 11].

Abbot and Howarth [52] also found that the link between training and policies that could back up staff decisions was missing, which led to staff feeling motivated yet powerless about introducing changes to the way they dealt with sexuality and relationships: "People would come on the training, raise awareness, all sorts of things would be disclosed and then they would say, 'But where's the back up for us in the workplace? You know, can we allow this? Should we stop that? What can we do about whatever?"' [52, p. 122]. Some studies also reported that lack of knowledge often led staff to seek external support or guidance from their seniors, which however was not always available or sufficient [27, 49]. 


\section{Subtheme 3: Uncertainty About Role}

Nine studies found that, partly due to the reported lack of guidelines and training, staff experienced a great deal of uncertainty about their role in dealing with the issues of sexuality and relationships [27, 29, 30, 32, 49, 51, 53-55]. Seven studies highlighted that staff members' uncertainty regarding their responsibilities meant that they were often left to respond to situations relating to sexuality and relationships intuitively and as they deemed appropriate $[29,30,32,49,51,53,54]$. In some cases, this allowed room for staff members' own values and moral judgments to influence decisions and led to inconsistent responses to incidents where input was required [29]: "That one would be a hard decision for me because I myself am not, I find pornography bad" [29, p. 61].

One study [32] highlighted that uncertainty became even greater in situations with a potential to be sexually unsafe or involving an element of risk, likely reflecting staff members' ongoing struggle between meeting service users' needs and protecting them, as well as protecting themselves. In some cases staff resolved this tension either by employing overly protective practices [32] or avoiding dealing with sexuality directly [29, 49, 51, 53]. As the following extract suggests, role uncertainty in some cases resulted in service users' rights to romantic and sexual expression being compromised as protection became a priority: “...in a sense we did palm it off, but there's nothing in our policies as, it comes back to policies and procedures, to say what we can and can't do or whether we cross the line." [53, p. 141].

\section{Influences on Decision-Making}

Several factors influencing decision-making in relation to issues concerning the sexual and romantic expression of individuals with ID were reported across studies. Such factors originated from employing organizations, as well as from staff themselves, service users and their families. It should be noted that, with a few exceptions, these influencing factors were most commonly described as barriers as opposed to factors that facilitated staff decision-making.

\section{Subtheme 1: Organizational Factors}

Eight studies reported that staff perceived organizational factors to play an important role in determining the degree to which service users' romantic and sexual needs could be met [30, 32, 49, 52-55, 57]. Four studies highlighted that the service culture and values, and when available, existing service policies were intolerant to the sexuality of individuals with ID and openly discouraged them from facilitating sexual expression [30, 49, 53, 54]: "The message is that we (as an organization) prefer that individuals are asexual and consequently try to redirect as much as possible" [30, p. 14]. Notably, only two studies [52, 54] provided evidence that policies in some services were viewed as helpful, for example by allowing service users access to private spaces where they could pursue intimate relationships [54]. The availability of clear rules also provided staff with certainty and legitimacy in the face of criticism for decisions made in relation to sexuality, thus reducing their fear about the potential consequences [52]: “They've got their own opinion but these are our policies and we can't change them. We showed them the policy and said, 'This is how we're going to work it... they're both consenting and we can't stop it."' [52, p. 121]. 
Six studies referred to the living environments of individuals with ID and the set up of services as major barriers to service users' ability to express themselves sexually and maintain relationships $[32,49,53-55,57]$. These included practical barriers, such as the lack of private spaces [32, 49, 53, 55], as well as restrictive regulations such as a requirement for room doors to be open $[54,55]$ : "Regarding roommates-time and place to set up for them to do it (e.g., masturbation)... it's difficult in this environment because they're not really allowed to-I feel they should be allowed (to masturbate)... to have a room to go fool around in- (but there is) no privacy-privacy is an issue'" [57, p. 356]. One study highlighted that organizational restrictions could lead individuals with ID to maintain a "double life" by expressing themselves sexually in secrecy, potentially compromising their safety and integrity [55]: "Recently I went to (facility) to do bandages for a girl who had made love in the park and her knees were completely frozen (...) (she had) third degree burns because it was winter and she had been on her knees." [55, p. 605].

\section{Subtheme 2: Fear of Accountability and Repercussions}

Seven studies reported that staff often experienced a great deal of fear in relation to taking responsibility for decisions made in the context of relationships and sexuality due to the potential personal and professional repercussions of such decisions [29, 30, 32, 49, 5153]. This fear was most commonly described in the context of organizations with either unclear or restrictive policies regarding the management of relationships and sexuality. For example, staff who experienced uncertainty about policies and their own role, frequently reported fear in relation to accidentally "crossing the line" and the negative career consequences this might incur [29, 30, 51, 52]. In some cases, staff resolved this tension by deferring responsibility to more knowledgeable colleagues or seniors [29, 51, 52]: "It would be quite hard if he says, 'I want this'. Sounds horrible but I don't think I'd want to, you know. I'd just get the manager involved and if something did go completely wrong it's on his shoulders isn't it?" [52, p. 120].

Similarly, staff employed by organizations with restrictive policies described these as limiting their ability to support the sexuality and relationships of service users. Such restrictive policies were often incongruent with staff values and attitudes and as such triggered feelings of discomfort or powerlessness regarding their role, as well as an acknowledgment that acting in a way that was consistent with their personal values would lead to career consequences [30,49]: "I'm sitting here and I feel like a complete hypocrite, because there is so much that I would love to be able to do but my hands are tied. If they (the clients) came to me and asked me for help I couldn't do it because my job and my neck would be on the line" [49, p. 35].

\section{Subtheme 3: Service User Factors}

The role of service user characteristics was another factor reported by ten studies as influencing decision-making around relationships and sexuality $[27,29,31,45,48,49,53$, $54,56,57]$. For example, staff described service users' level of intellectual functioning as influencing their ability to process educational materials and as such meaningfully participate in conversations about sex and reproduction [27, 31, 53], navigate relationships on the Internet [48] and consent to relationships [57]: "I guess with people with high support needs, it's also unclear, I mean how would you go about providing some kind of sexual health education to someone who has no skills whatsoever and their cognitive ability is really, really low" [53, p. 144]. In addition, staff were more likely to prioritize protection 
over autonomy for those perceived as being of lower ability [49], perceive people with profound ID as less likely to have sexual needs [29] as well as less able to control themselves and understand social norms relating to sexuality [54].

Certain individual characteristics such as level of pre-existing sexual knowledge and ability to control oneself sexually [54] were also perceived as factors facilitating staff involvement with issues surrounding sexuality. Gender was only mentioned by two studies $[54,56]$ as a factor influencing how staff managed the issues of sexuality and relationships. These suggested that men were viewed as more driven by sexual motives when entering relationships [56] and less able to control their sexual impulses than women $[54,56]$, which led to women being perceived as more innocent, sexually naïve and vulnerable [56].

\section{Subtheme 4: The Role of Family Caregivers}

Family caregivers were identified by nine studies as playing a key role in staff's ability to support issues around sexuality and relationships [27, 29, 31, 32, 49, 51-54]. In the majority of studies, this involvement was perceived as a barrier due to family caregivers directing if and how the issue of sexuality should be managed [30, 51, 52] and as having the potential to limit or prohibit their adult children's sexual expression and autonomy [27, 31, 49, 51-54]: "We basically can't meet the sexual health needs of the client, because the parents are giving us directives as to, this is how it's going to be" [53, p. 143]. In some cases of family caregivers who opposed to decisions aimed at facilitating sexual expression, staff feared that negative reactions could lead to formal complaints, which further complicated their ability to fulfill their role [51].

At the same time, there was an acknowledgement that, when family caregivers acted as facilitators and supported their children's desire to be involved in relationships, this involvement was invaluable due to the amount of influence they had on other parents [54]: "We've got such a group of parents- leaders, very open, moving forward, aware of their children's needs- not just eating and drinking but also sexual ones. And they attended this training session (on sexuality of people with ID) and they encouraged others to join it as well" [54, p. 82]. Of note is, however, that findings regarding the positive contributions of family caregivers in this area were only reported by one study, suggesting that the role of family caregivers was largely viewed as a barrier as opposed to a facilitator.

\section{Discussion}

The present review suggests that staff perceptions and attitudes towards the sexuality and relationships of individuals with ID are ambivalent, a finding that perhaps explains the inconclusive findings of attitudinal research in this area [12-18] and is consistent with those of previous qualitative reviews $[11,25,26]$. Although staff across several studies embraced the normalization discourse and articulated a desire and moral commitment to supporting service users with sexual needs, they also voiced cautious attitudes towards their sexuality. Sexual expression was also described as a source of risk and a challenge, suggesting that it continues to be viewed in the context of risk and vulnerability [64]. Of note is that, although attitudes were arguably not openly negative or discriminatory, participants in some of the included studies acknowledged that negative attitudes were still common amongst staff in their organizations [51-54]. It is therefore possible to conclude that a degree of social desirability may prevent staff from expressing openly negative views 
within studies or more likely, that staff holding openly negative or discriminatory attitudes may be more likely to be underrepresented in research due their exclusion by self-selection bias [65].

The findings of this synthesis indicate that staff tended to respond to issues relating to sexuality and relationships in an equally conflicted manner. An exploration of the interplay between factors underlying this conflicted stance revealed that staff were required to perform their roles in a complex ethical landscape characterized by multiple power struggles and pressures. Similarly to the findings of previous reviews [11, 26], the ethical complexity most frequently cited by participants across studies was related to the issue of vulnerability and protection, which appeared to trigger both personal and systemic anxiety. In this synthesis, family caregivers were also identified by staff as a source of pressure, with such findings likely reflecting the commonly reported fearful attitudes parents hold towards their children's sexuality $[10,66,67]$, which reportedly tend to be more conservative than those of staff $[10,12]$. Service culture and values, as well as restrictive policies within organizations were also found to complicate staff's ability to respond to service users' sexual needs. Compared to previous reviews of research with staff, this synthesis highlighted a greater number of organizational barriers and restrictions to sexual expression, such as limited privacy and strict regulations. Such findings are consistent with those of studies that have involved individuals with ID, which show that the set up of services and existing regulations, pressures and rules often make intimate relationships an impossible task [5, 64].

Staff's struggle to juggle external pressures appeared to be further exacerbated by a lack of training. This finding is widely consistent with existing research showing that, despite the documented effectiveness of training programs in shifting attitudes towards sexuality [68], there is a clearly identified deficit in sexuality training within services [10, 69]. Lack of training, combined with an absence of clear policies [10], created a sense of uncertainty amongst staff regarding their roles. This subsequently led to a great deal of fear regarding the potential repercussions of taking responsibility for service users' sexuality and relationships, which has also been reported by a previous review [11]. Fear and uncertainty could in some cases further reinforce a passive attitude towards sexuality or lead to the delivery of inconsistent messages for individuals with ID. Such findings would be consistent with a large body of research with individuals with ID, who report that staff often respond to issues of sexuality selectively and inconsistently [5] and have described rules within services as unclear $[70,71]$.

\section{Implications for Individuals with ID}

Staff attitudes and practices towards the sexuality and relationships of the individuals they support can have significant implications on how they perceive themselves as sexual beings. By avoiding or actively discouraging sexual expression, staff may ultimately convey the message that sexuality is not an option for service users or reinforce the idea that it is dangerous and forbidden $[64,72]$. This can create a self-fulfilling prophecy where individuals with ID internalize this view and either refrain from expressing their sexuality or engage with sexuality in secrecy $[5,71,72]$, thus putting themselves at potentially greater risk. Additionally, a perception of service users who are less cognitively able or lack sexual knowledge as less likely to be supported to express their sexuality [29, 48, 49], can potentially create a self-perpetuating cycle whereby service users who need it the most are the least likely to receive education and support to fulfill their romantic and sexual needs. 
The findings of the present synthesis suggest that negative or even discriminatory messages in relation to certain aspects of the sexuality of individuals with ID are still likely to be communicated. This is more likely to be the case in relation to pregnancy and parenthood [32, 54, 57], as well as to the relationships and sexual expression of gay, lesbian or bisexual individuals with ID [51,52, 56]. Research in the area of attitudes towards same-sex relationships in individuals with ID suggests that discriminatory responses from staff can be subtle, yet present [52]. For example, a recently published study amongst LGBT + disabled youth [73] found that attraction to members of the same sex was often delegitimized, by being described as a 'phase' or a result of their disability, and individuals with ID themselves were often viewed as incapable of making informed choices about their sexuality due to their disability. Such findings suggest that certain groups of individuals with ID may be more likely to experience discrimination within their environments, with this having the potential to cause isolation and lead to confusion and shame about their sexual identity.

\section{Implications for Staff and Services}

The findings of this review further emphasize the requirement for service policy development specifically in relation to sexuality and relationships, which based on the present findings, is most often either absent or restrictive. The availability of clear policies within services can ensure that service users' rights are not violated, but also provide staff with a guideline which can alleviate concerns regarding accountability and repercussions from employing organizations or family caregivers. As policy development is inextricably connected to funding and identified service priorities [53], it is likely that for such changes to occur at a service level, there needs to be a shift in national policy priorities. In that direction, the Care Quality Commission in the UK has recently published a guidance for relationships and sexuality in adult social care services [74], which outlines the responsibilities of service providers in meeting those areas of need for service users. Although this is a promising step, ongoing monitoring of the implementation of such guidelines may be required and policy with a more specific focus on ID and sexuality might need to be developed. Hopefully, such developments can gradually lead to a change in culture within services and the elimination of disempowering and restrictive views.

In agreement with previous authors $[11,25,26]$, the present review concludes that sufficient and timely training on sexuality is necessary. However, it is worthwhile considering whether traditional training may not be sufficient. For example, based on the findings of the present synthesis, training is more likely to be effective if it maintains close links with policy regarding the implementation of knowledge in practice and within specific staff roles, otherwise, it can lead to a sense of powerlessness [51]. Additionally, with sexuality in the population of individuals with ID being an ethically complex and provocative subject, training may need to be supplemented with opportunities for staff to engage in reflective practice and more meaningful supervision and modeling by senior members of staff. This could help staff manage external pressures and allow them to reflect on how their own values and attitudes may interfere with their practice. Lastly, given the extremely influential role of family caregivers in decision-making surrounding sexuality, it is likely that training tailored to their needs is a prerequisite for any meaningful change in the way such matters are managed within services. 


\section{Strengths and Limitations}

Given the growing interest of qualitative research on the experiences of staff in relation to supporting the sexuality of individuals with ID, this review is valuable as it provides an up to date overview and quality appraisal of available research. Unlike previous recent reviews conducted in this subject area $[25,26]$, the qualitative synthesis of previous findings in this review enabled the aggregation of participant perspectives from multiple studies and allowed for an in depth exploration and demonstration of staff attitudes and practices, as well as of the interplay between factors influencing these. By highlighting such processes and factors influencing decision-making and staff practices, the present review was able to combine existing knowledge and use it to make recommendations for practice.

A possible limitation of the present review is related to the well-documented [36] difficulties inherent in searching for qualitative literature in electronic databases. Of note is that a quarter of the articles included in this review were identified through a manual search. Although all measures were taken to avoid the accidental omission of relevant studies, for example by contacting other researchers in this area, there is still potential for human error. Furthermore, in this review a decision was made to exclude gray literature. Although such a decision has the benefit of ensuring the quality of articles through the process of peer review, it is possible that the inclusion of unpublished research, such as dissertations and theses, might have enriched the findings and would have reduced publication bias [75].

Although the present review aimed to include studies using samples of a wide range of staff, there was an over-representation of support workers in the overall sample of included studies and therefore this may have impacted on the nature of themes that emerged as important. For example, as direct care staff are less likely to have received sexuality training compared to staff employed in managerial or clinical roles [69], it is possible that themes related to role uncertainty and powerlessness are more relevant to that professional group compared to others. Nevertheless, attention was paid during the analysis to ensure that produced themes were, as much as possible, representative of the dataset overall in order to mitigate the risk of providing a biased picture of staff experiences.

\section{Research Recommendations}

Future primary research, as well as reviews may find useful to more specifically consider exploring the experiences and views of other professional groups that remain largely under-represented in research, such as nurses, doctors, social workers and psychologists. Given the crucial role of service managers in the implementation of training and policy as well as in overseeing staff working practices, exploring their views can valuably add to our understanding of how service cultures can shift and adapt to meet the romantic and sexual needs of service users. Future research should also consider the role of family caregivers, especially considering the key role they play in enabling staff to support individuals with ID to meet their romantic needs.

The findings of this review in relation to the ambivalence in staff attitudes and practices suggest that further quantitative research exploring the impact of staff and environmental factors on these is needed. This might be particularly useful in the further exploration of findings regarding the prevalence of negative or discriminatory attitudes towards certain aspects of the sexuality of individuals with ID, such as parenthood and same-sex relationships. Additionally, it might be helpful for future qualitative and quantitative evaluations 
of sexuality training programs for staff to consider the potential contribution of additional elements, such as reflective practice and supervision, to outcomes related to attitudes and practices. Lastly, future research might benefit from more specifically determining the severity of individuals' ID when exploring staff attitudes and practices, due to the potential presence of complicating factors associated with guardianship and capacity to consent amongst individuals with severe ID.

Authors' Contributions All involved authors participated in the planning and design of this review, as well as in on-going supervision of the main author and review of the results and discussion. The main author was responsible for the overall write up of this review.

Funding This review did not receive any grants from public, commercial, or not-for profit sector funding agencies.

Availability of Data and Material (Secondary) data and materials used in this research are available.

\section{Compliance with Ethical Standards}

Conflict of interest The authors declare that they have no conflict of interest.

Consent for Publication Consent for publication has been received by all authors.

Open Access This article is licensed under a Creative Commons Attribution 4.0 International License, which permits use, sharing, adaptation, distribution and reproduction in any medium or format, as long as you give appropriate credit to the original author(s) and the source, provide a link to the Creative Commons licence, and indicate if changes were made. The images or other third party material in this article are included in the article's Creative Commons licence, unless indicated otherwise in a credit line to the material. If material is not included in the article's Creative Commons licence and your intended use is not permitted by statutory regulation or exceeds the permitted use, you will need to obtain permission directly from the copyright holder. To view a copy of this licence, visit http://creativecommons.org/licenses/by/4.0/.

\section{References}

1. Culham, A., Nind, M.: Deconstructing normalisation: clearing the way for inclusion. J. Intellect. Dev. Dis. 28(1), 65-78 (2003)

2. Fulford, C., Cobigo, V.: Friendships and intimate relationships among people with intellectual disabilities: a thematic synthesis. J. Appl. Res. Intellect. 31(1), 18-35 (2018)

3. Shakespeare, T.: Disabled sexuality: toward rights and recognition. Sex. Disabil. 18(3), 159-166 (2000)

4. The Scottish Government: The Keys to life-Improving the Quality of Life for People with Learning Disabilities (2013). http://www.gov.scot/resource/0042/00424389.pdf. Accessed 22 May 2019

5. English, B., Tickle, A.: Views and experiences of people with intellectual disabilities regarding intimate relationships: a qualitative metasynthesis. Sex. Disabil. 36(2), 149-173 (2018)

6. Emerson, E., Hatton, C.: Deinstitutionalization in the UK and Ireland: outcomes for service users. J. Intellect. Dev. Dis. 21(1), 17-37 (1996)

7. Forrester-Jones, R., Carpenter, J., Coolen-Schrijner, P., Cambridge, P., Tate, A., Beecham, J., Wooff, D.: The social networks of people with intellectual disability living in the community 12 years after resettlement from long-stay hospitals. J. Appl. Res. Intellect. 19(4), 285-295 (2006)

8. Siebelink, E.M., de Jong, M.D., Taal, E., Roelvink, L.: Sexuality and people with intellectual disabilities: assessment of knowledge, attitudes, experiences, and needs. Ment. Retard. 44(4), 283-294 (2006)

9. Servais, L.: Sexual health care in persons with intellectual disabilities. Ment. Retard. Dev. Disabil. Res. 12(1), 48-56 (2006) 
10. Evans, D.S., McGuire, B.E., Healy, E., Carley, S.N.: Sexuality and personal relationships for people with an intellectual disability. Part II: staff and family carer perspectives. J. Intell. Disabil. Res. 53(11), 913-921 (2009)

11. Rushbrooke, E., Murray, C.D., Townsend, S.: What difficulties are experienced by caregivers in relation to the sexuality of people with intellectual disabilities? A qualitative meta-synthesis. Res. Dev. Disabil. 35(4), 871-886 (2014)

12. Cuskelly, M., Bryde, R.: Attitudes towards the sexuality of adults with an intellectual disability: parents, support staff, and a community sample. J. Intellect. Dev. Dis. 29(3), 255-264 (2004)

13. Drummond, E.: Attitudes towards sexuality: a pilot study in Ireland. Learn. Disabil. Pract. 9(4), 28-34 (2006)

14. Gilmore, L., Chambers, B.: Intellectual disability and sexuality: attitudes of disability support staff and leisure industry employees. J. Intellect. Dev. Dis. 35(1), 22-28 (2010)

15. Tamas, D., Jovanovic, N.B., Rajic, M., Ignjatovic, V.B., Prkosovacki, B.P.: Professionals, parents and the general public: attitudes towards the sexuality of persons with intellectual disability. Sex. Disabil. 37(2), 245-258 (2019)

16. Bazzo, G., Nota, L., Soresi, S., Ferrari, L., Minnes, P.: Attitudes of social service providers towards the sexuality of individuals with intellectual disability. J. Appl. Res. Intellect. 20(2), 110-115 (2007)

17. Grieve, A., McLaren, S., Lindsay, W., Culling, E.: Staff attitudes towards the sexuality of people with learning disabilities: a comparison of different professional groups and residential facilities. Br. J. Learn. Disabil. 37(1), 76-84 (2009)

18. Van de Mortel, T.F.: Faking it: social desirability response bias in self-report research. Aust. J. Adv. Nurs. 25(4), 40 (2008)

19. Saxe, A., Flanagan, T.: Factors that impact support workers' perceptions of the sexuality of adults with developmental disabilities: a quantitative analysis. Sex. Disabil. 32(1), 45-63 (2014)

20. Pebdani, R.N.: Attitudes of group home employees towards the sexuality of individuals with intellectual disabilities. Sex. Disabil. 34(3), 329-339 (2016)

21. Bryman, A.: Social Research Methods. Oxford University Press, New York (2015)

22. Evans, D., Pearson, A.: Systematic reviews of qualitative research. Clin. Eff. Nurs. 5(3), 111-119 (2001)

23. Lachal, J., Revah-Levy, A., Orri, M., Moro, M.R.: Metasynthesis: an original method to synthesize qualitative literature in psychiatry. Front. Psychiatry 8, 269 (2018)

24. Tong, A., Flemming, K., McInnes, E., Oliver, S., Craig, J.: Enhancing transparency in reporting the synthesis of qualitative research: ENTREQ. BMC Med. Res. Methodol. 12(1), 181 (2012)

25. Chrastina, J., Večeřová, H.: Supporting sexuality in adults with intellectual disability-a short review. Sex. Disabil. (2018). https://doi.org/10.1007/s11195-018-9546-8

26. Brown, M., McCann, E.: The views and experiences of families and direct care support workers regarding the expression of sexuality by adults with intellectual disabilities: a narrative review of the international research evidence. Res. Dev. Disabil. 90, 80-91 (2019)

27. Höglund, B., Larsson, M.: Ethical dilemmas and legal aspects in contraceptive counselling for women with intellectual disability_focus group interviews among midwives in Sweden. J. Appl. Res. Intellect. 32(6), 1558-1566 (2019)

28. Höglund, B., Larsson, M.: Midwives' work and attitudes towards contraceptive counselling and contraception among women with intellectual disability: focus group interviews in Sweden. Eur. J. Contracept. Reprod. 24(1), 39-44 (2019)

29. Maguire, K., Gleeson, K., Holmes, N.: Support workers' understanding of their role supporting the sexuality of people with learning disabilities. Br. J. Learn. Disabil. 47(1), 59-65 (2019)

30. Martino, A.S., Perreault-Laird, J.: "I don't know if I can talk about that": an exploratory study on the experiences of care workers regarding the sexuality of people with intellectual disabilities. Disabil. Stud. Q. 39(3), 1041-5718 (2019)

31. Neuman, R.: Attitudes of direct support staff regarding couple relationships of adults with intellectual disability: implications for the provision of support. J. Soc. Serv. Res. (2019). https://doi. org/10.1080/01488376.2019.1648361

32. Pariseau-Legault, P., Holmes, D., Ouellet, G., Vallée-Ouimet, S.: An ethical inquiry of support workers' experiences related to sexuality in the context of intellectual disabilities in Quebec, Canada. Br. J. Learn. Disabil. 47(2), 116-125 (2019)

33. France, E.F., Wells, M., Lang, H., Williams, B.: Why, when and how to update a meta-ethnography qualitative synthesis. Syst. Rev. 5(1), 44 (2016)

34. World Health Organization: ICD-10: International Statistical Classification of Diseases and Related Health Problems: Tenth Revision, 2nd edn. World Health Organisation, Geneva (2004) 
35. American Psychiatric Association: Diagnostic and Statistical Manual of Mental Disorders, 5th edn. American Psychiatric Association, Wahsington, DC (2013)

36. Evans, D.: Database searches for qualitative research. J. Med. Libr. Assoc. 90(3), 290-293 (2002)

37. Williams, V., Boylan, A.M., Nunan, D.: Qualitative research as evidence: expanding the paradigm for evidence-based healthcare. BMJ Evid. Based Med. 24(5), 169 (2019)

38. Dixon-Woods, M., Shaw, R.L., Agarwal, S., Smith, J.A.: The problem of appraising qualitative research. BMJ Qual. Saf. 13(3), 223-225 (2004)

39. Critical Appraisal Skills Programme UK: CASP checklists (2019). https://casp-uk.net/casp-tools-check lists/. Accessed 5 Nov 2019

40. Noyes, J., Booth, A., Flemming, K., Garside, R., Harden, A., Lewin, S., Pantoja, T., Hannes, K., Cargo, M., Thomas, J.: Cochrane qualitative and implementation methods group guidance series-paper 3: methods for assessing methodological limitations, data extraction and synthesis, and confidence in synthesized qualitative findings. J. Clin. Epidemiol. 97, 49-58 (2018)

41. Butler, A., Hall, H., Copnell, B.: A guide to writing a qualitative systematic review protocol to enhance evidence-based practice in nursing and health care. Worldviews Evid. Based Nurs. 13(3), 241-249 (2016)

42. Thomas, J., Harden, A.: Methods for the thematic synthesis of qualitative research in systematic reviews. BMC Med. Res. Methodol. (2008). https://doi.org/10.1186/1471-2288-8-45

43. Carroll, C., Booth, A., Leaviss, J., Rick, J.: "Best fit" framework synthesis: refining the method. BMC Med. Res. Methodol. (2013). https://doi.org/10.1186/1471-2288-13-37

44. Campbell, R., Pound, P., Morgan, M., Daker-White, G., Britten, N., Pill, R., Yardley, L., Pope, C., Donovan, J.: Evaluating meta-ethnography: systematic analysis and synthesis of qualitative research. Health Technol. Assess. (2011). https://doi.org/10.3310/hta15430

45. Malterud, K.: Qualitative research: standards, challenges, and guidelines. Lancet 358(9280), 483-488 (2001)

46. Moher, D., Liberati, A., Tetzlaff, J., Altman, D.G.: Preferred reporting items for systematic reviews and meta-analyses: the PRISMA statement. Ann. Intern. 151(4), 264-269 (2009)

47. Randolf, J.J.: Online Kappa Calculator. http://justusrandolph.net/kappa/. Accessed 10 Jan 2020

48. Löfgren-Mårtenson, L., Sorbring, E., Molin, M.: "Tangled Up in Blue": views of parents and professionals on internet use for sexual purposes among young people with intellectual disabilities. Sex. Disabil. 33(4), 533-544 (2015)

49. Lafferty, A., McConkey, R., Simpson, A.: Reducing the barriers to relationships and sexuality education for persons with intellectual disabilities. J. Intellect. Dev. Dis. 16(1), 29-43 (2012)

50. Saxe, A., Flanagan, T.: Unprepared: an appeal for sex education training for support workers of adults with developmental disabilities. Sex. Disabil. 34(4), 443-454 (2016)

51. Parkes, N.: Sexual issues and people with a learning disability. Learn. Disabil. Pract. 9(3), 32-37 (2006)

52. Abbott, D., Howarth, J.: Still off-limits? Staff views on supporting gay, lesbian and bisexual people with intellectual disabilities to develop sexual and intimate relationships? J. Appl. Res. Intellect. 20(2), 116-126 (2007)

53. Thompson, V.R., Stancliffe, R.J., Broom, A., Wilson, N.J.: Barriers to sexual health provision for people with intellectual disability: a disability service provider and clinician perspective. J. Intellect. Dev. Dis. 39(2), 137-146 (2014)

54. Ćwirynkało, K., Byra, S., Żyta, A.: Sexuality of adults with intellectual disabilities as described by support staff workers. Hrvat. Rev. Rehabil. Istraz. 53, 77-87 (2017)

55. Pariseau-Legault, P., Holmes, D.: Mediated pathways, negotiated identities: a critical phenomenological analysis of the experience of sexuality in the context of intellectual disability. J. Nurs. Res. 22(8), 599-614 (2017)

56. Young, R., Gore, N., McCarthy, M.: Staff attitudes towards sexuality in relation to gender of people with intellectual disability: a qualitative study. J. Intellect. Dev. Dis. 37(4), 343-347 (2012)

57. Wilkenfeld, B.F., Ballan, M.S.: Educators' attitudes and beliefs towards the sexuality of individuals with developmental disabilities. Sex. Disabil. 29(4), 351-361 (2011)

58. Hamilton, C.: Doing the wild thing: supporting an ordinary sexual life for people with intellectual disabilities. Disabil. Stud. Q. 22(4), 40-59 (2002)

59. Carroll, C., Booth, A.: Quality assessment of qualitative evidence for systematic review and synthesis: is it meaningful, and if so, how should it be performed? Res. Synth. Methods 6(2), 149-154 (2015)

60. Pearson, A.: Balancing the evidence: incorporating the synthesis of qualitative data into systematic reviews. JBI Rep. 2(2), 45-64 (2004) 
61. Carroll, C., Booth, A., Lloyd-Jones, M.: Should we exclude inadequately reported studies from qualitative systematic reviews? An evaluation of sensitivity analyses in two case study reviews. Qual. Health Res. 22(10), 1425-1434 (2012)

62. Atkins, S., Lewin, S., Smith, H., Engel, M., Fretheim, A., Volmink, J.: Conducting a meta-ethnography of qualitative literature: lessons learnt. BMC Med. Res. Methodol. (2008). https://doi. org/10.1186/1471-2288-8-21

63. Smith, J.A.: Evaluating the contribution of interpretative phenomenological analysis. Health Psychol. Rev. 5(1), 9-27 (2011)

64. Grace, N., Greenhill, B., Withers, P.: "They just said inappropriate contact". What do service users hear when staff talk about sex and relationships? J. Appl. Res. Intellect. 33(1), 39-50 (2020)

65. Robinson, O.C.: Sampling in interview-based qualitative research: a theoretical and practical guide. Qual. Res. Psychol. 11(1), 25-41 (2014)

66. Pownall, J.D., Jahoda, A., Hastings, R.P.: Sexuality and sex education of adolescents with intellectual disability: mothers' attitudes, experiences, and support needs. Intellect. Dev. Disabil. 50(2), 140-154 (2012)

67. Manor-Binyamini, I., Schreiber-Divon, M.: Parental perceptions of the sexuality of adolescents with intellectual disabilities. Sex. Disabil. 37(4), 599-612 (2019)

68. Chou, Y.C., Lu, Z.Y.J., Chen, B.W., Lin, C.J.: 'Transformed rights' sexual health programme evaluation for the parents and service workers of adults with an intellectual disability. J. Intell. Disabil. Res. 63(9), 1125-1136 (2019)

69. McConkey, R., Ryan, D.: Experiences of staff in dealing with client sexuality in services for teenagers and adults with intellectual disability. J. Intell. Disabil. Res. 45(1), 83-87 (2001)

70. Healy, E., McGuire, B., Evans, D., Carley, S.: Sexuality and personal relationships for people with an intellectual disability. Part I: service-user perspectives. J. Intellect. Disabil. Res. 53(11), 905-912 (2009)

71. Rushbrooke, E., Murray, C., Townsend, S.: The experiences of intimate relationships by people with intellectual disabilities: a qualitative study. J. Appl. Res. Intellect. 27(6), 531-541 (2014)

72. Kelly, G., Crowley, H., Hamilton, C.: Rights, sexuality and relationships in Ireland: 'It'd be nice to be kind of trusted'. Br. J. Learn. Disabil. 37(4), 308-315 (2009)

73. Toft, A., Franklin, A., Langley, E.: 'You're not sure that you are gay yet': the perpetuation of the 'phase' in the lives of young disabled LGBT + people. Sexualities 23(4), 1-14 (2019)

74. Care Quality Commission: Relationships and sexuality in adult social care services. Guidance for CQC inspection staff and registered adult social care providers (2019). https://www.cqc.org.uk/sites/default/ files/20190221-Relationships-and-sexuality-in-social-care-PUBLICATION.pdf. Accessed 8 Jan 2020

75. Paez, A.: Gray literature: an important resource in systematic reviews. J. Evid. Based Med. 10(3), 233240 (2017)

Publisher's Note Springer Nature remains neutral with regard to jurisdictional claims in published maps and institutional affiliations. 